\title{
Low-carbon development strategy for the West African electricity system: preliminary assessment using System dynamics approach
}

\author{
Abiodun Suleiman Momodu ${ }^{1,2^{*}}$ D, Ahmad Addo ${ }^{3}$, John-Felix Kayode Akinbami ${ }^{1}$ and Yacob Mulugetta ${ }^{4}$
}

\begin{abstract}
Background: Policy makers seek to understand the trade-offs needed between economic growth and climate change. This provides the context to explore low-carbon development (LCD) pathways for the West African electricity system.

Methods: The study relied on both primary and secondary sources to elicit required information. These data were elicited from relevant authorities in the West African electricity system, namely, West African Power Pool and ECOWAS Regional Electricity Regulatory Authority. The objectives were to evaluate the planning processes in the West African Power Pool electricity system vis-a-vis low-carbon development strategy (LCDS), develop a System dynamics (SD) model, and assess the relevance of the developed model to examine the nonlinear relationship between generation adequacy and greenhouse gas emission (GHG) reduction. The SD model examined the tension between providing adequate supply capacity against reducing emission from the generation technologies in the West Africa electricity system. This model arranged the complexities in the system and established the basic interconnecting structure to conduct the analysis. High leverage points were identified.
\end{abstract}

Results: Four high leverage points were identified: capacity factor (CF), emission factor (EF), time to adjust capacity, and expectation formation. CF and EF improvement increased efficiency in the system. The expectation formation periods were determined at 7.5 years for the base case scenario and 7 years for the low-carbon development option scenario. Time to adjust capacity was located at 21 and 20 years respectively; deduced from the average time, it will take to construct a combined cycle gas power plant (3 years) and an allowance of 2 years for delays and its decommissioning time. Between 2011 and 2012, in LCD option scenario, emission of GHG to the atmosphere dropped as generation did but began a steady rise for the simulation period to a value of 6.154 billion $\mathrm{tCO}_{2}$ in 2060 .

Conclusions: Electricity Planning-Low-Carbon Development (EP-LCD) model—with three modules, was developed for assessing WAPP in low carbon economy. High leverage points identified in the model simulation situate three policy options for overcoming poverty and mitigation targets as regards resource mix, investment cost recovery, and technical factors to reduce system's environmental footprint.

Keywords: Low carbon development, Electricity system, WAPP, Feedback loop, Leverage points

\footnotetext{
* Correspondence: abiodunmomodu8@gmail.com; amomodu@cerd.gov.ng; asmomodu@knust.edu.gh

'Obafemi Awolowo University, Ile-lfe, Nigeria

${ }^{2}$ CIRCLE Postdoctoral Visiting Fellow, The Energy Centre, College of

Engineering, Kwame Nkrumah University of Science and Technology, Kumasi,

Ghana

Full list of author information is available at the end of the article
} 


\section{Background}

Climate change is currently recognized as one of the most complex, multifaceted, and serious threats the world faces [1]. This recognition gave rise to the need to find a way to simultaneously address climate change and at the same time help to advance developmental aspirations. Low-carbon development is a development paradigm that contributes to addressing these twin challenges of the 21st century. It seeks to promote economic growth or sustainable development while keeping greenhouse gas (GHG) emissions low or lower than without interventions. This gave rise to the concept of Low-Carbon Development Strategies (LCDS). This strategy, introduced by the Conference of Parties to the United Nations Framework Convention for Climate Change (UNFCCC), represents a common but differentiated approach to meet the overall emission reduction objectives. LCDS in this way become an overarching framework to design and achieve Nationally Appropriate Mitigation Actions (NAMAs) reflecting the common but differentiated responsibility (CBDR) of all countries. Although there is no internationally agreed definition of LCDS, this study focuses on integrated climate and lowcarbon development strategies that cover the intersection of development and GHG mitigation in West Africa power sector. The focus on power sector is without prejudice to the impact that transport sector makes to GHG emissions from the subregion. Adaptation issues included are those that relate to mitigation actions.

While large-scale economic development is needed to pull millions of citizens out of abject poverty by government/regulators, investors, and development partners, "business-as-usual" approach would exacerbate the problem of climate change with potentially irreversible long-term consequences. Conceptualizing and implementing LCDS have formidable challenges, needing systemic approach; this is a different planning paradigm from what used to be the norm in planning the power sector [2-4].

West Africa member states need rapid transformation to enhance the standard of living of the populace. This will involve adequate provision of needed infrastructure such as energy including electricity for socioeconomic development. Nonetheless, achieving this transformation needs ample understanding of the trade-offs between economic growth and development aspiration on the one hand, and climate change issues on the other. Now, it can be argued that the subregional desire to develop should precede that of global environmental concern in ranking. However, it is important that this developmental pursuit be done with some sense of responsibility to the environment [5]. Development is energy driven, meaning that energy use drives economic growth and in turn, economic growth drives energy use. As at 2013, the estimated population of West Africa was put at about 340 million with Nigeria contributing over $50 \%$ of this; the average annual growth rate is estimated at $2.8 \%$ [6]. Incidentally, countries in the West African subregion are blessed with an abundant supply of various kinds and categories of energy resources though skewed towards some countries like Nigeria, Ghana, and Cote d'Ivoire. Being in the tropic, it is blessed with abundant solar insolation and other renewable energy types coupled with vast reserves of hydrocarbons-coal, oil, and natural gas among fossil fuel reserves. Despite these vast resources, access to electricity in the subregion has remained at less than $50 \%$ in the urban areas and less than $20 \%$ in rural areas.

Relating this to climate change, it is noted that anthropogenic GHG emissions are mainly driven by population size, economic activity, lifestyle, energy use, land-use patterns, technology, and climate policy [7]. This means that if adequate precautions are not taken, even though West Africa subregion is considered among the non-Annex 1 countries, with its population size, economic activity, and energy, the subregion could well become a prime source for future GHG emission. With a relatively large population size coupled with the desire to increase electricity generation capacity to meet future demand, it is imperative that the subregion adopts a strategic intervention for her energy consumption agenda. Non-Annex I Parties are mostly developing countries without any obligation to meet any defined emission target under the Kyoto Protocol. Though business-as-usual is projected for non-Annex 1 countries' emissions, in the absence of any new climate policies to control this, projections showed that by 2050 , emissions in all non-Annex 1 regions would need to be substantially reduced below business-as-usual [8] Agreeably, there is the need to increase all infrastructural capacity; however, this needs to be done with the mind of not repeating pre-industrial age errors of the industrialized countries. Thus, for West African countries and any other emerging economies at that, without any strategic intervention, the quest to increase production capacity in the power sector would definitely take the same trajectory as those of developed countries and cause undesired increase in the release of GHG emissions to the atmosphere. The emission of these GHG will occur at levels quite higher than what obtains when compared to its past and current level [8-10]. In line with global expectations, it becomes important to develop LCDSs for the power sector in the West African subregion and considering the importance of this critical infrastructure to economic growth, hence the need for this study.

The study identified and tested two basic scenarios of low-carbon development options for the power sector in 
the West African subregion to contain the level of emission anticipated from the sector in the future. Thus, the questions the study addressed coupled with the broad objective informed the specific objectives of:

a. Evaluating the planning processes in the WAPP electricity system vis-a-vis LCDS

b. Developing a SD model for the WAPP power sector

c. Assessing the relevance of the developed model to examine the nonlinear relationship between generation adequacy and GHG emission reduction

Olsina, Garcés and Haubrich [10], Olsina [11], Ford [12], Abbas [13], and among others have all used System dynamics approach to examine various developmental issues, particularly as related to energy and electricity. This study follows in line with such studies bringing out the policy implications and trade-offs needed to achieve LCD strategy in the West African electricity system. The "Background" section of the paper introduces the issues of challenges of developing the electricity system in West Africa against GHG emission reduction, pointing out the existing tension between them. The "West Africa and the West African Power Pool" section investigates the West African electricity system, efforts to harness the regional resource in the sector for development, global climate change obligations of member states, and approaches to modeling of long-term electric power markets. The "Methods" section describes the methodology, discussing the conceptual framework, data gathering, research design and procedures, model and scenario development, and identification of leverage points for policy analysis. Result and analysis to look at model workings, model outputs in the two scenarios, and among others are examined in the "Results" section. This section also highlights the lesson learnt from the model simulation, policy implication, and trade-offs needed to pull the West African electricity system away from its current state. The study concludes in "Conclusions" section with recommendations on the enhancement of the adoption of efficient electricity systems while exploring the variety of ways the countries could encourage renewable energy usage among the populace.

\section{West Africa and the West African Power Pool}

Energy use, particularly electricity is projected to rise in the nearest future. At an average economic growth rate of about $6 \%$ annually, the demand for electricity is also projected to grow in the same or higher proportion. The implication is not far-fetched in terms of GHG emissions, depending on the choice of the mix of power plants that would be needed to meet the future demand for electricity. There is currently a footprint of power sector in terms of GHG emissions in West Africa. This study, based on SD modeling is however to look at the low emission capacity that could be achieved within the electricity system as related to other spheres and sectors within the economy.

Nigeria situates West Africa in the global map of being currently among the highest gas flaring regions. West African countries project a future power generation requirements and peak demand at $5.8 \%$ annual growth rate. ${ }^{1}$ It is inevitable that the subregion pursues an approach that responds adequately to global climate change obligations and meets with this projection of future generation requirements. West Africa is endowed with coal and other hydro resources that could also be increased or added to energy mix which is presently dominated by natural gas and large hydro resources to use for power generation. The WAPP is set up as a cooperation of the national electricity companies in Western Africa under the auspices of the Economic Community of West African States (ECOWAS). The WAPP, which currently comprises 14 of the 15 member countries of ECOWAS (Benin, Burkina Faso, Cote d'Ivoire, The Gambia, Ghana, Guinea, Guinea Bissau, Liberia, Mali, Niger, Nigeria, Senegal, Sierra Leone, and Togo) are working to establish a reliable power grid for the region and a common market for electricity.

The WAPP member states cover a surface area of 5105 million $\mathrm{km}^{2}$. In terms of electricity supply infrastructure, Nigeria dominates the WAPP as shown in Table 1. For WAPP electricity production, Nigeria contributed about $57 \%$ to the total of $38,826.6$ million $\mathrm{kWh}$ that was consumed in 2010. In this period however, the WAPP system could only have an available capacity of 9550 MW, which represents $58 \%$ out of the 16,391.7 MW total installed capacity. It follows that the system can benefit from improvement to increase its energy output. The WAPP power system covers two geographical zones $\mathrm{A}$ and $\mathrm{B}$, each consisting of interconnected systems, which, according to ECOWAS vision 2015, should be connected together to facilitate electricity trade in the region. WAPP Zone A Member States include Cote d'Ivoire, Ghana, Togo, Nigeria, Niger, Burkina Faso, and Benin. They are all presently interconnected under the following border interconnections:

- Cote d'Ivoire - Burkina Faso, Cote-d'Ivoire - Ghana Togo - Benin - Nigeria; export emanates mainly from Cote d'Ivoire, Ghana, and Nigeria to other countries; however, Ghana imports from Cote d'Ivoire.

- Nigeria - Niger; the bulk of electricity needs to Niger are met by supply from Nigeria.

The major strategic resources available for electricity generation in the West African region include crude oil, coal, natural gas, and hydropower. Coal is used in a very 
Table 1 Electricity supply structure of the WAPP

\begin{tabular}{llll}
\hline Country & Generation, transmission, and distribution & Electricity production (million kWh) [3] & \% Contribution \\
\hline Benin & Société Béninoise d'Énergie Électrique and Communauté Électrique du Bénin & 124 & 0.3 \\
Burkina Faso & Société Nationale d'électricité du Burkina Faso & 611.6 & 1.6 \\
Côte d'Ivoire & Société de Gestion du Patrimoine du Secteur de l'Electricité (SOGEPE) & 5275 & 13.5 \\
The Gambia & National Water and Electricity Company (NAWEC) & 160 & 0.4 \\
Ghana & Volta River Authority and Electricity Company of Ghana & 6746 & 17.3 \\
Guinea & Electricité de Guinée & 850 & 2.2 \\
Guinea Bissau & Electricidade e Aguas da Guine-Bissau & 65 & 0.2 \\
Liberia & Liberian Electricity Corporation & 350 & 0.9 \\
Mali & Energie du Mali & 515 & 1.3 \\
Niger & Société Nigérienne d'Électricité" (NIGELEC) & 397 & 1.0 \\
Nigeria & Various companies & 21,920 & 180 \\
Senegal & Société d'Électricité du Sénégal & 56.2 \\
Sierra Leone & National Power Authority (Sierra Leone) & 80 & 4.8 \\
Togo & Togo Electricité and Communauté Électrique du Bénin & 0 & 0.2 \\
& Total & $38,973.6$ & 0.0
\end{tabular}

low quantity in Niger Republic. Some countries already have biomass in their energy mix while others like Nigeria and Ghana have plans to incorporate renewable energy sources, aside from hydropower, into their energy $\operatorname{mix}[14,15]$.

\section{Climate change and subregional responsibility}

At the meeting of the Conference of Parties (COP) 19, held in Warsaw in November 2013, Parties to the UNFCCC decided (Decision 1/CP.19) "to invite all Parties to initiate or intensify domestic preparations for their Intended Nationally Determined Contributions (INDCs), without prejudice to the legal nature of the contributions, in the context of adopting a protocol, another legal instrument or an agreed outcome with legal force under the Convention applicable to all Parties towards achieving the objective of the Convention as set out in its Article 2 and to communicate them well in advance of the twenty-first session of the Conference of the Parties (by the first quarter of 2015 by those Parties ready to do so) in a manner that facilitates the clarity, transparency and understanding of the intended contributions, without prejudice to the legal nature of the contributions". This decision was reiterated at COP 20, held in Lima 2014 (1/CP.20, "Lima Call for Climate Action"). Parties also agreed in Lima that INDCs, towards achieving the objective of the Convention, should represent a progression beyond current mitigation efforts and prevent backsliding. The commitment of the Parties to the INDCs is such that countries agreed to publicly outline what actions they intend to take under a global agreement well before the Paris Summit (and for those countries in a position to do so, by March 2015). Their form and rigor will largely determine whether the world achieves an ambitious 2015 agreement and is put on a path towards a low-carbon, climate-resilient future. This study is an attempt at a first step to developing a rigorous analytical approach to adopting low carbon strategy in the electricity sector of West Africa. A follow-up study to the current effort will involve a disaggregation of information used in the model to develop country level strategy. This is to help achieve a platform for regional and country level INDC $[16,17]$.

\section{Targeting low-carbon economy with the WAPP electricity system}

Without doubt, increasing emissions of GHG have led to a marked increase in atmospheric GHG concentration. A large amount of the increase in atmospheric GHG concentration has been traced to energy related activities. Energy related activities that have brought about the largest growth in global GHG emissions since 1970 are from energy supply sector and transportation. Electricity sector is an energy supply sector that also depends on the use of primary energy sources such as oil, natural gas, and coal for its fuel use. Recent study by the World Bank [18] on Low-Carbon Development shows that by 2035 emissions from energy-related activities will contribute more than $80 \%$ of total emissions. Also, the recent IPCC Fifth Assessment Synthesis Report [3] indicates that developing countries or emerging economies cannot afford to rely on business-as-usual approach to climate change-related issues.

As revealed later in the study, countries in West Africa are energy-deprived and are yet to attain the peak in their electricity consumption. This may imply a propensity to 
increase emission from increased energy consumption in the electricity sector in the future. IPCC [3] identifies that anthropogenic GHG emissions are mainly driven by population size, economic activity, lifestyle, energy use, land-use patterns, technology, and climate policy. With population and economic activity projected to grow progressively on an annual basis coupled with the electricity needed to play the key role in catalyzing developmental process, there will be relative and absolute increase of GHG emissions from the energy sector. That is if the business-as-usual scenario to achieve the growth pathway is taken. However, a low-carbon economy approach leaves considerable scope for West African countries to introduce low-carbon development strategy that will achieve the same development objectives while at the same time lowering future emissions. Energy-related mitigation options that could be examined include demand-side energy efficiency improvement options, increased use of renewable energy, supply side energy efficiency improvement options, increased natural gas utilization, use of less carbon-intensive fuel in the transport sector, and transport mode shift to mass transit. This study limits its approach to developing the SD model to examine the complex interactions of the electricity system in achieving lowcarbon emission option.

\section{Approach to modeling of long-term electric power markets} Long-term modeling approach by participating firms in electric power markets are usually with the use of optimization-based techniques [19].When the formulation of this technique is based on the assumption of optimal resource allocation, it is known as partial equilibrium model. The assumption usually made is that the perfect competition is "perfect," and incumbent firms will behave rationally. These kinds are currently focused predominantly on the short term, though some few long-term markets based on optimization techniques exist. These latter techniques are formulated on the assumption that resource allocation resulting from the market mechanism is equivalent to the minimization of the discounted, cumulated operating and investments over the considered planning horizon. It is important to also point out that there are optimization-based models that do not rely on the assumption of perfect competition [20]. Mirzaesmaeeli [21] developed multi-period optimization model for electricity planning with $\mathrm{CO}_{2}$ considerations. The model was formulated using an objective function that minimizes the net present value of the cost of electricity (COE) over a time horizon of 14 years. This model could be classified as a medium term model based on its time horizon. Further work on kinds of available optimization models for the analysis of electric power market performance can be found in [22].
Generally, optimization-based models present prescriptive approach of the system it analyzes [10, 23]. They describe the behavior of the system under ideal condition, though this description may not always be verifiable in true or real markets. Their advantage stems from their serving principally as benchmarks on what the market behavior should do. For their mathematical solution however, this model usually needs important simplifications. In spite of this, one major limitation to these models is that they commonly neglect the existence of feedback and time constants in the systems being examined. The implication of this neglect is that under this modeling approach, the system response or performance is viewed only as a sequence of stable and optimal long-run equilibrium state.

On the other hand, the econometric and simulative models are inherently descriptive, that is, they describe outputs of phenomena of interest, e.g., will the building collapse in an earthquake? If I follow this course of action, what will happen? In terms of electric power modeling however, econometrics approach has not been so extensively applied to long-term performance. Though quite a number of reasons could be adduced for this, the principal one that could be deduced is that dealing with dynamic systems will be difficult using static relationship and not by means of market fundamentals. Literature reveals that these models are instead applied to long-term demand forecasting related to other fundamental parameters such as population and economic growth and electricity prices. Good examples of such approach are the model presented by [24, 25].

Unlike the econometric models, simulative models currently enjoy an increased interest for their flexibility in modeling the actual behavior of power markets. One principal advantage they have is their suitability for capturing soft characteristics present in real markets like bounded rationality, learning abilities, and information asymmetries [22]. There are presently two separate streams of literature covering the development of simulation methods.

First is the modeling discipline grounded on the system theory and control engineering, and applied mainly to business and managerial systems. This modeling discipline is known as System dynamics (SD) and is focused on the macroscopic structure of the system under study. It also deals with the interrelationships among the systems' components in order to explain the dynamical behavior. This approach implies the formulation of the differential equation representing the time response of system variables, which generally describes attributes at an aggregate level. Bunn and Larsen [26] and Ford [27] presented a very simplified version of the first causal loop diagrams of a liberalized power market describing the dynamical terms of the market balancing mechanism responsible for maintaining adequate supply 
reliability levels. The limitations of these studies as observed by Olsina, Garcés and Haubrich [10], is that they did not present the mathematical formulation and characterization of the dynamical state equation representing the power market.

Agent-based modeling (ABM) is the second and more recent modeling approach in the computational and simulation. This is at the micro and unattached (corpuscular) level though seems to be a modeling discipline gaining significant attention. Most of the attraction of this approach is based on the possibility to model heterogeneity, autonomy, and individuality $[10,28]$. Agents pose some rational limitations in the decision making rules they use but exhibit some abilities to learn from the environment. The aggregate system behavior emerges from the interaction among the elemental and evolving entities. Though, these two approaches are radically different perspectives, SD and ABM models must deliver equivalent descriptions of the systems at the aggregate levels. Currently, the relationships between both approaches are being intensively investigated [29-31].

The flexibility of the SD model informed its selection to model the long-term performance of WAPP electric power system particularly considering superimposing LCDS on it. By its definition, the quantitative modeling approach using SD principles will allow this study to query various likely courses of actions (LCD models) in a computer-based model.

\section{System boundary and general research approach}

The electric power system is characterized as a structural model [10], having a bottom-up approach, since the long-run development of the power market is determined by modeling the variables having direct influence on long-term movements of supply and demand. Figure 1 presents a simple description of power and money flow in the West African electricity system depicting WAPP and ERERA. Figure 2 shows the interconnection in the WAPP. For the WAPP interconnections, the regulatory arrangement is such that ERERA, as the specialized institution of ECOWAS, has the main objective of regulating interstate electricity exchanges and of giving appropriate support to national regulatory bodies or entities of the Member States. So ERERA handles interstate regulation in the "wired segment" of the WAPP, functioning presently as the WAPP Market/System operator handling interstate power exchange, while national entities are responsible for the Market/System operation within their national boundaries. It is expected that when an Independent Market operator is created out of WAPP, it will be primarily responsible for the implementation of the Market Rules.

In order to demonstrate the simulation focus, the required inputs and the system boundary of the research

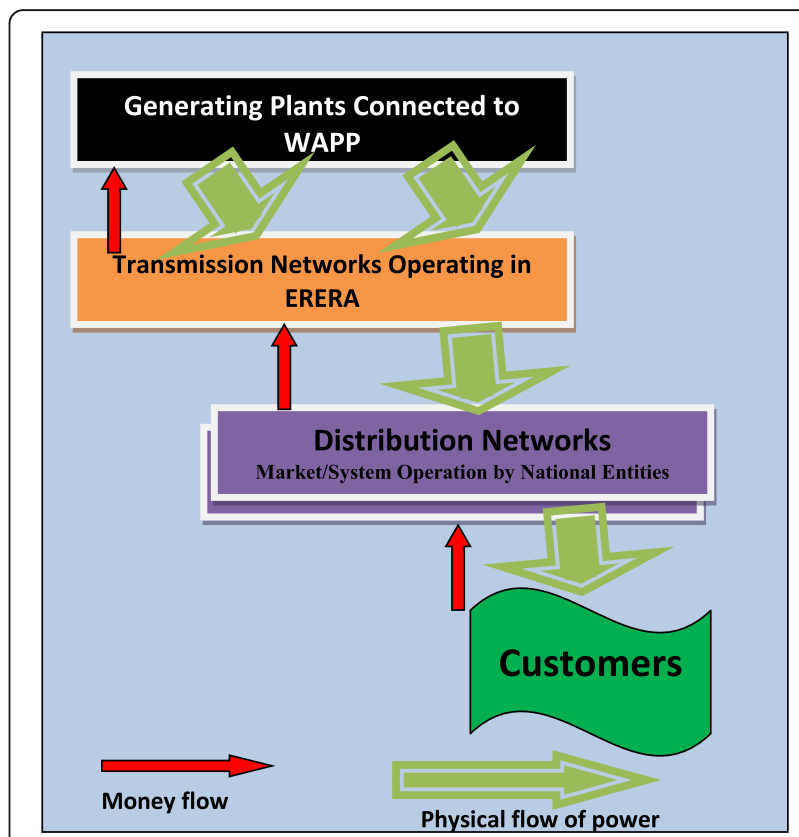

Fig. 1 Simple flow chart representation of interconnections in West African electricity system

approach, a bull's eye diagram of the model as adapted from Kilanc and Or [32] is presented in Fig. 3. In the bull's eye diagram, endogenous variables are placed in the center of the bull's eye; exogenous variables are placed in the outer frame. Excluded variables are placed outside the outer frame. The bull's eye diagram is a convenient way to show the relative balance between required inputs (exogenous variables) and endogenous variables. If endogenous variables are more, this is a good sign indicating that the "model generates interesting dynamic behavior from within the system" [27]. If a variable appears somewhere in a feedback loop, or it is influenced by another variable that is in a feedback loop, then the related variable is said to be an endogenous variable in the model.

\section{Methods}

The framework for this study is based on achieving lowcarbon development strategy for the power sector in West Africa. The most important outcome of the study using the model for analysis is to develop a platform that will make electricity system in West Africa an ambitious, transparent, and equitable one that is able to attract investments in a timely manner to increase the generation capacity through more efficient technologies.

\section{Conceptual framework}

The conceptual framework for analysis of the data elicited was developed using feedback control system based on SD principles. Figure 4 shows the interconnectivity of 

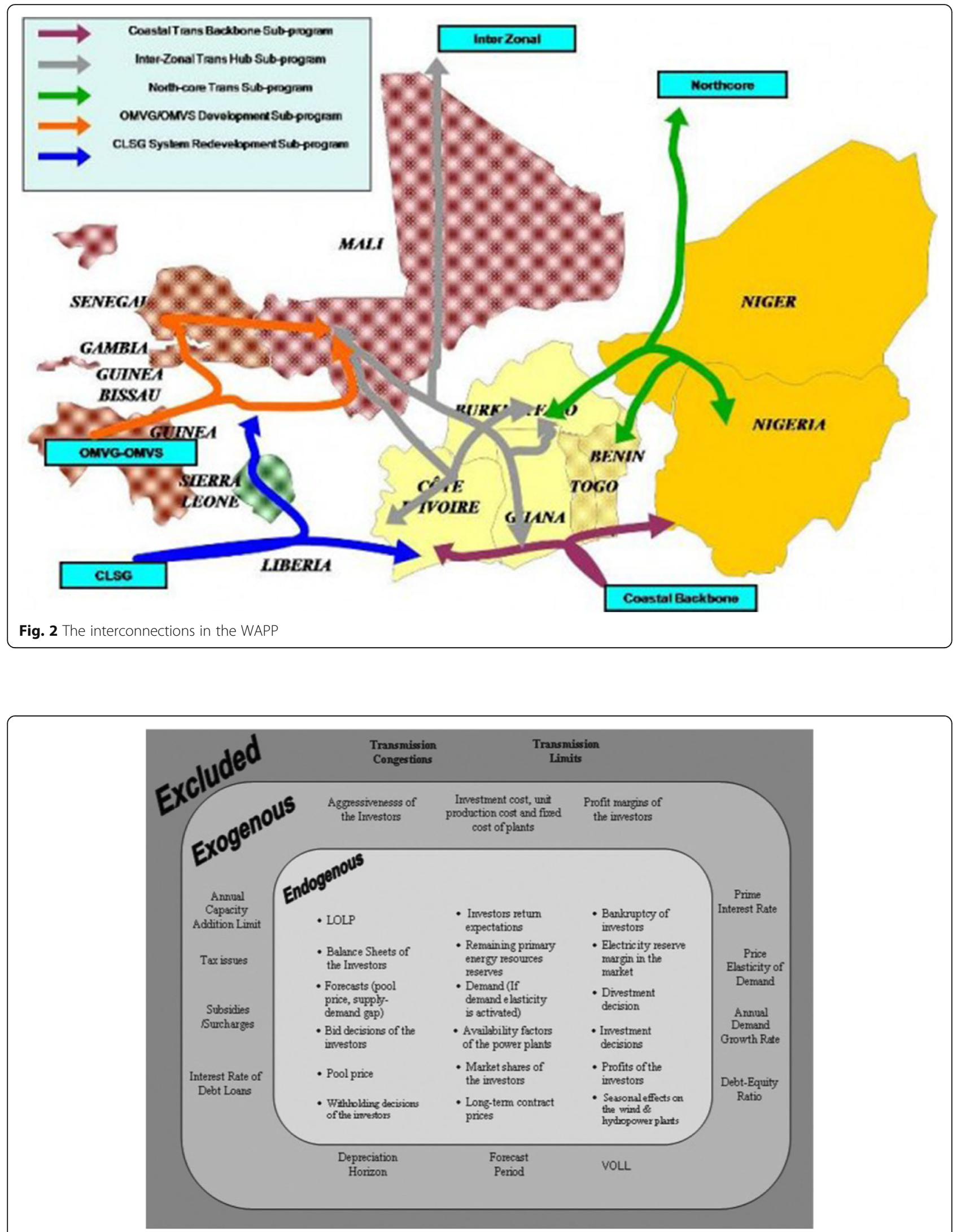

Fig. 3 Bull's eye diagram of the model (adapted from [32]) 


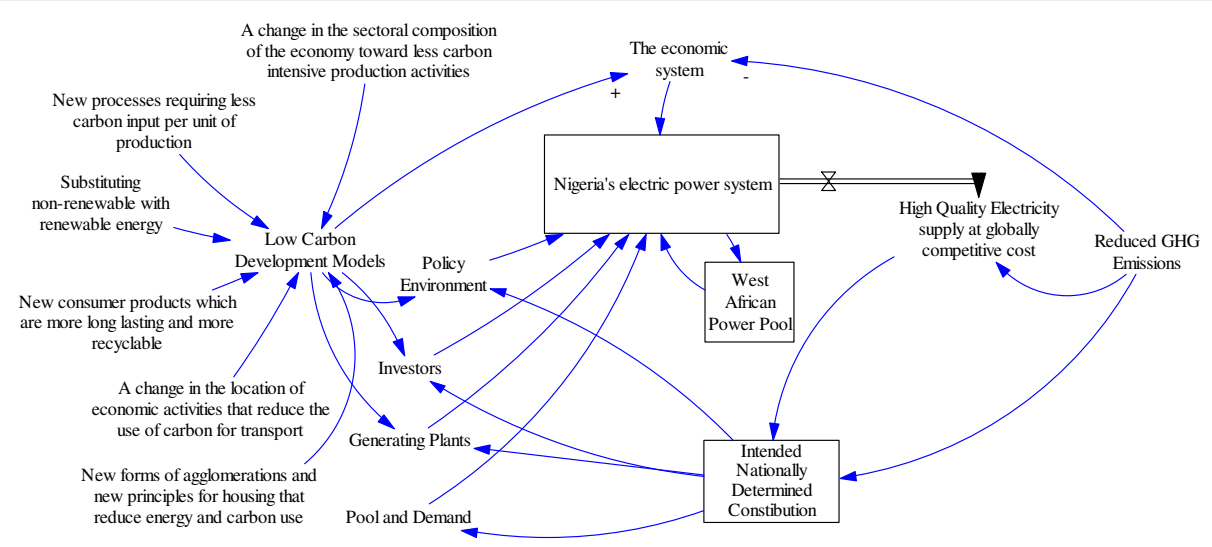

Fig. 4 Causal loop diagram depicting study conceptual framework

the subsystems of economic, LCD, and power sector evaluation. Reduced emission using LCD approach is imposed on the existing electric power system to develop the model used to evaluate its effect on projected increment in the subregional electricity consumption level. This was done from evaluation of a combination of the various available LCD models, projected economic growth rate and INDC for the subregion that will allow for sustainable development. In its current form, most of the electric power systems in the subregion experience unsatisfied demand met mostly by self-generation or no supply at all. Hopefully, with liberalization of the system, the suppressed demand could be reduced or eliminated.

LCDS imposition on the power system in the WAPP is expected to generate new regulations and rules (bureaucracy) that may demand new or modified organizational structures for implementation. The model is also made up of the aggregation of the supply side of the system under study, consisting of generation, transmission, distribution system operation, and retail trading. The model output segment is made up of the performance of the utility which is measured by the electric power demand met in GWh through the generation capacity in MW as well as the reduced GHG emission achieved in the power sector.

Using of feedback control system based on SD principles, the causal loop diagram for the conceptual framework used in the study is as presented in Fig. 4.

\section{Data gathering}

As a follow-up to that in [9], the study relied on both primary and secondary data sources to elicit required information. Primary data were sourced from the regional bodies responsible for electricity development through the use of questionnaire instrument [33] administered to the relevant authorities in the West African subregion, namely, WAPP, ERERA, and ECREEE. Variables (such as population, generation capacity, scrapping rate, and tariff) related to electricity market model development were considered in developing the questionnaire. Secondary data were sourced from various developed electricity market models and regulatory approaches. The developed quantitative model [34], formed the principal means of arranging the complexities in the West African electricity system and was used to conduct the analysis after the basic interconnecting structure of the system was established in the model.

\section{LCDS and power sector analysis}

Since the study is limited to the power sector alone, the options considered were limited to alternatives to current generation technologies and reduction in Transmission and Distribution Losses. Other options like demand side management to reduce emission in the electricity system is looked at in another study. These are presented in Table 2 and are incorporated to the model as LCDS.

\section{Research design and procedures}

The design of the study took the following into consideration. First step involved the capture of data that are useful for electricity planning and management in West African electricity system from secondary sources for the period under review. Data analysis was carried out using descriptive and inferential statistics, where necessary. A combination of the outcome of these exercises, including low-carbon development strategy formed the key inputs for examining a long-term performance of the WAPP. The timeframe for this study was 50 years starting from 2011.

\section{Model development}

The System dynamics model conceptualization was based on Zagonel and Corbet [34] and Sterman [35]. Its structure was developed based on a review of the operations of the WAPP electricity system. Electricity Planning-Low-Carbon Development (EP-LCD) model is 
Table 2 Options considered for low-carbon strategy in WAPP electricity system

\begin{tabular}{lll}
\hline Low-carbon technology & Reference technology & Remark \\
\hline Off-grid hybrid wind-diesel & Off-grid diesel gen & Generation technology \\
Off-grid solar PV & Off-grid diesel gen & Generation technology \\
Small hydropower & Off-grid diesel gen & Generation technology \\
Wind turbines & Simple cycle gas turbine (SCGT) & Generation technology \\
Concentrating solar thermal power (CSP) & SCGT & Generation technology \\
Solar PV (grid) & SCGT & Generation technology \\
Biomass & SCGT & Generation technology \\
Hydropower & SCGT & Generation technology \\
Supercritical coal with carbon capture and storage (CCS) & Subcritical coal & Generation technology \\
Combined cycle gas turbine (CCGT) & SCGT & Generation technology \\
EE CFL lighting (grid) & Incandescent lighting & Demand side management \\
EE CFL lighting (off-grid) & Incandescent lighting & Demand side management \\
T \& D losses & Improved system operations & T \& D
\end{tabular}

Source: World Bank [38]

organized in spheres and sectors and was customized following a modular approach. Table 3 shows all of its spheres and sectors (with sectors being the building blocks of the higher level aggregation represented by the spheres). The structure of the model was developed based on the objective $2^{2}$ of the WAPP as well as WAPP's vision and mission that aims to make the electricity system in the ECOWAS subregion to be operated as a merchant power market when an enabling environment for this kind of operation is achieved [36]. The capacity addition component in the system can be represented in two ways to explain the dynamics of the electric power markets, and these have been well described in Olsina, Garcés and Haubrich [10] and Musango et al. [37]. These two

Table 3 Sectors and spheres in electricity-low-carbon development model

\begin{tabular}{ll}
\hline Social-economic sphere & Population \\
& Production \\
& Government accounts \\
& Industrial growth \\
& Gross Domestic Product \\
& Generation capacity \\
& Transmission distribution/electricity \\
Electricity sphere & Ponsumption \\
& Electricity marketing \\
& New processes requiring less carbon \\
& input per unit of production \\
& Substituting nonrenewable with \\
& renewable energy \\
LCD sphere & Energy efficiency target \\
& GHG mitigation target \\
\hline
\end{tabular}

representations are its causal-loop and the stock-and-flow diagramming, respectively, and they take the present operational conditions of the WAPP into consideration to develop the model for simulating internal behavior dynamics. This dynamics is described by a set of nonlinear differential equations that account for existing system feedbacks, delays, stock-and-flow structures, and nonlinearities. The EP-LCD model is largely focused on electricity operations and interconnections in the WAPP power system as well as carbon dioxide emitted from the system.

EP-LCD model is distinguished by the manner in which various sectors and spheres are connected together to form a complex link of feedback loops in which the electric system can be analyzed and weighted as driving or limiting the subregion's LCD agenda. Further description of basic feedback structure of a simplified causal-loop for electric power system is in Olsina, Garcés and Haubrich [10] and Musango et al. [37] and is presented in Fig. 5 to provide an overview of the system's dynamical structure and to guide further

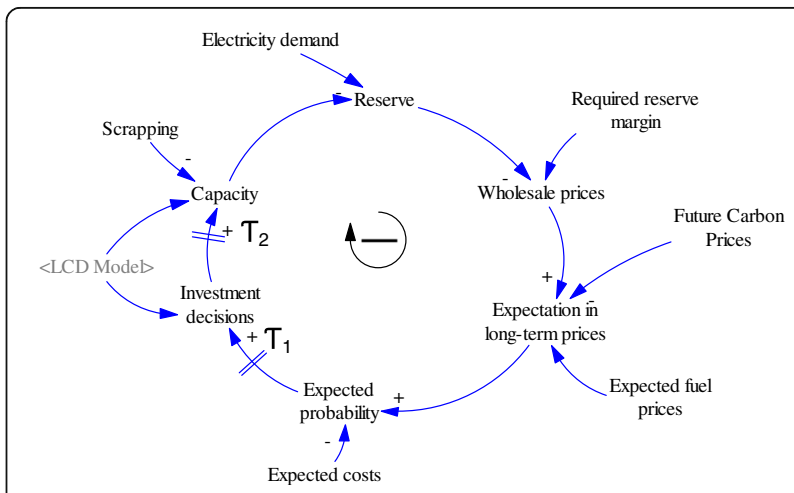

Fig. 5 Causal loop diagram (CLD) of a typical electric power system (adopted from Olsina 2005) 
discussions in modeling the different system components. The diagram shows the basic balancing feedback that governs the long-term development of any power market. In developing the model, market participants were taken into consideration. Market participants form expectation on the future electricity prices on the basis of current market conditions and expected fuel prices as well as future carbon trading prices. These expected prices play a crucial role in determining the profitability of possible investment projects. This implies that construction of new power plants is predicated on the assurance that there is enough certainty of investment cost recovery. This expectation was embedded into the Social and Economic Spheres of the model. Therefore, the first delay in the feedback loop is in regard of irreversibility of investment, that is, the investment decision delay, denoted with $T_{1}$. In addition to this delay, new power plants are required to get permissions at stipulated LCD standard and they need a certain time to be constructed and to be brought online. This forms the second delay on the feedback loop and is denoted in Fig. 5 as $T_{2}$. The existing capacity plus the additions of new capacity, the scrapping/ decommissioning of old power plants and the current system demand will determine the new reserve margin and the new prevailing price level. Added to this is that the technology choice considered in developing the model was based solely on available primary energy resources in the subregion. Some of these technologies, like those using natural gas, have variants in terms of their operational design. With this therefore, the market becomes selfbalancing and resembles the negative feedback loops commonly encountered in control systems. This balancing mechanism is responsible for maintaining an adequate reserve margin to ensure a reliable electricity supply.

However, this causal loop diagram (CLD) is useful to represent the causal relationships and the market balancing feedbacks responsible for adjusting the production capacity, though it is not capable to show explicitly stock-and-flow structures embedded in the system. Figure 5 shows the structure of delay $T_{1}$ and $T_{2}$ in a typical electric power system.

\section{Estimating off-grid generation}

Electricity in the West African countries is generated from both grid and off-grid sources to meet the demand. The source categories are presented in Table 4. This captures all sources from which electricity is generated in the subregion, particularly in Nigeria. However, projecting the future of off-grid generation is extremely challenging especially due to inadequate data. For this reason, studies of power systems for developing countries have usually ignored off-grid generation. Thus, given the large contribution of off-grid generation in some West African countries, which is unlikely to
Table 4 Source categories of electricity supply in West African countries

\begin{tabular}{ll}
\hline Supply source/category & Description \\
\hline Grid-supply & $\begin{array}{l}\text { Generation from the power grid } \\
\text { Off-grid A; backup } \\
\text { power is unavailable }\end{array}$ \\
Off-grid B; full time $\geq 1 \mathrm{MW}$ & $\begin{array}{l}\text { Off-grid generation which is used full } \\
\text { time even though there is grid access, } \\
\text { with generators greater than or equal to } \\
1 \mathrm{MW} \text { (which require government } \\
\text { registration) }\end{array}$ \\
& $\begin{array}{l}\text { Off-grid generation used full time even } \\
\text { though there is grid access, with } \\
\text { Off-grid C; full time }<1 \mathrm{MW}\end{array}$ \\
& $\begin{array}{l}\text { generators under 1 MW (not needing } \\
\text { government registration) } \\
\text { Generation in rural locations with no } \\
\text { grid access }\end{array}$ \\
\hline
\end{tabular}

Source: World Bank [38]

disappear entirely within 25 years, ignoring it would seriously compromise the practical value of the study. There is no way a good assessment of emissions from electricity sector would be done without accounting for off-grid generation. Consequently, off-grid generation was included in the model development, to enable the model development and its output to be complete. As data become available, this is better refined, though there would still be the inevitable uncertainty. Nevertheless, estimating current off-grid capacity and generation could be daunting for countries prone to paucity of data. In Nigeria, for example, generators of $1 \mathrm{MW}$ or greater must be registered, but there are limited data on actual usage and the capacity of other off-grid generation beyond some local surveys. For the present run, the study by World Bank [38] was adopted. The study examined the effects of this uncertainty via a sensitivity analysis, asking what the results would be if 2009 off-grid generation was $40 \%$ less or $40 \%$ more than the current estimate. This was assumed for entire simulation period in the model for the base case, and the same off-grid generation mix over time as described below for each scenario. The resulting emission was then evaluated using this assumption.

\section{Identification of leverage points in the model}

Leverage points are places within a complex system (a corporation, an economy, a living body, a city, and an ecosystem) where a small shift in one thing can produce big changes in everything ([35]. This idea is not unique to system analysis. Leverage points are points of power in a system that modelers not only believe in but would want to know where they are and how to locate them. According to Forrester quoted in Meadows [39], "leverage points are not intuitive. Or if they are, we intuitively use them backward, systematically worsening 
whatever problems we are trying to solve." There are steps to help identify places of intervention in a system, and these served as a guide in this study as listed in Meadows [39].

The inflow-electricity generation and investment-and financial flow increase the stock while the outflowtransmission and distribution-losses and thefts decrease it. So the bedrock of this system consists of physical stocks and flows, obeying the laws of conservation and accumulation. Now, the challenge in the WAPP power system is principally inadequacy; meaning that the inflow rate is lower than the outflow rate, making the non-storable commodity to be in shortfall always. As it takes time for systems to respond to desired growth, it is also for flows to accumulate. This is the same observation with the electricity system in WAPP; it will take time to correct the anomalies making it to be sluggish in responding to desired changes. It is critical, however, to be able to identify the "leverage points" along the line of the operations of the electricity system in WAPP with the superimposed LCD models and the corrective measures to achieve desired objectives as enunciated in the objectives, vision, and mission of WAPP.

Systems have at least two negative feedback loops or correcting loops [39]; one controls the inflow and the other one controls the outflow, either or both of which can be used to bring the system to a desired level. It is important to point out that the goal and the feedback connections are not visible in the system. But a "long enough watch" over the system will enable one to figure out what are the leverage points in it. This study involves superimposing a new paradigm-LCD-into the planning of an already complex system; the Nigeria electricity system coupled with the WAPP power system to bring out future plan that is responsive to delivering electricity that is globally cost competitive and at the same time achieving desired INDCs. Identifying the leverage point in the system cannot be done intuitively but through counterintuitive approach. Further details on places to intervene in a system are described in Meadows [39].

\section{Scenario development and sensitivity analysis}

Sensitivity testing is the process of changing your assumptions about the value of constants in the model and examining the resulting output [40]. Parameters of System dynamics models are subject to uncertainty, so sensitivity analysis is an important task for the reliability of simulation results [41]. Since System dynamics is a behavior-oriented simulation discipline, sensitivity of behavior pattern measures, such as equilibrium level or oscillation amplitude to the model parameters, should be evaluated in order to explore the effects of parameter uncertainty on the behavior patterns.
Vensim $^{\circ}$ software has the capability to do repeated simulations in which model parameters are changed for each simulation. This can be very helpful in understanding the behavioral boundaries of a model and testing the robustness of model-based policies. To do a sensitivity simulation, a list of parameters must be entered that will be changed in the model. The list of parameters used in this model is presented in later section. Manual sensitivity testing involves changing the value of a constant (or several constants at once) and simulating, then changing the value of the constant again and simulating again, and repeating this action many times to get a spread of output values. Monte Carlo simulation, also known as multivariate sensitivity simulation (MVSS), makes this procedure automatic. Hundreds or even thousands of simulations can be performed, with constants sampled over a range of values, and output stored for later analysis.

Two scenarios, base case and LCD options on the WAPP electricity system were analyzed. The base case scenario represents continuing with business-as-usual using technologies in the electricity system as they currently are without consideration for efficiency and how they contribute to global warming through emission of GHG into the atmosphere. The LCD options on the other hand, represents the use of technologies with higher efficiency and low-carbon emission to replace generation technologies that have high emitting factors. Table 5 shows the parameters used in the base case scenario and Table 6 those used in LCD option scenario. These include capacity factor (a ratio), capacity lifetime (measured in years), emission factor (measured as carbon dioxide released per unit of electricity generated), normal per capita electricity demand (measured as electricity consumed per person in a given year), and time to adjust capacity (measured in years). The model is made up of seven parameters that are subscripted.The high leverage points for policy intervention were identified from these seven parameters, which were used to conduct sensitivity analysis on the model. Out of the four identified, three, namely, capacity factor, emission factor, and time to adjust capacity are represented in these tables. The fourth is expectation formation. These were identified after the use of multivariate sensitivity simulation (MVSS) or Monte Carlo simulation to sift out the other multiple parameters identified in the model as possible high leverage points.

\section{Results}

\section{Brief description of model workings}

As an approach to understanding different organizations, markets and other complex systems and their dynamic behavior, it was possible to use SD to model the West African electricity system as it relates to other sectors. The different sectors are segmented as modules 
Table 5 Base case parameters in the EP-LCD model

\begin{tabular}{|c|c|c|c|c|c|c|c|c|}
\hline & Fuel type & $\begin{array}{l}\text { Capacity } \\
\text { (MW) }\end{array}$ & $\begin{array}{l}\text { Capacity factor } \\
(\mathrm{Dmnl})\end{array}$ & $\begin{array}{l}\text { Capacity lifetime } \\
\text { (years) }\end{array}$ & $\begin{array}{l}\text { Construction } \\
\text { time (years) }\end{array}$ & $\begin{array}{l}\text { Emission factor } \\
\left(\mathrm{tCO}_{2} / \mathrm{MWh}\right)\end{array}$ & $\begin{array}{l}\text { Normal per capita } \\
\text { electricity demand } \\
\text { (MWh/person) }\end{array}$ & $\begin{array}{l}\text { Time to adjust } \\
\text { capacity (years) }\end{array}$ \\
\hline \multirow{6}{*}{$\begin{array}{l}\text { Grid } \\
\text { technologies }\end{array}$} & Residual fuel oil & 1410 & 0.48 & 25 & 3 & 0.2786 & \multirow[t]{11}{*}{0.146} & \multirow[t]{11}{*}{20} \\
\hline & Gas & 4892 & 0.48 & 25 & 3 & 0.2020 & & \\
\hline & Hydropower & 3760 & 0.48 & 50 & 10 & 0.0 & & \\
\hline & Coal & 32 & 0.48 & 25 & 8 & 0.3413 & & \\
\hline & Nuclear & 0 & 0 & 25 & 10 & 0 & & \\
\hline & Solar & 0 & 0 & 25 & 2 & 0 & & \\
\hline \multirow{4}{*}{$\begin{array}{l}\text { Renewablegrid } \\
\text { technologies }\end{array}$} & Biomass & 0 & 0 & 25 & 2 & 0 & & \\
\hline & Wind & 0 & 0 & 25 & 2 & 0 & & \\
\hline & $\begin{array}{l}\text { Diesel } \\
\text { generators }\end{array}$ & 1695.12 & & & & 0.2667 & & \\
\hline & $\begin{array}{l}\text { Gasoline } \\
\text { generators }\end{array}$ & 2118.9 & & & & 0.2496 & & \\
\hline $\begin{array}{l}\text { Off-grid } \\
\text { technologies }\end{array}$ & Gas turbines & 423.78 & & & & 0.2020 & & \\
\hline
\end{tabular}

Sources: World Bank (2013) [38]; WAPP (2014); [42]

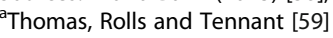

as presented in Fig. 6. The model is referred to as Electricity Planning-Low-Carbon Development (EP-LCD) Model. It was meant to analyze low-carbon emission in West Africa electricity system. Before further analysis of the model, it is important to describe the variable types for developing it. The model was developed using basic System dynamics variables. Explaining variables is often difficult without reference to equations, but it is useful to have a complete categorization and specify conventions.
Vensim $^{\circ}$ software is designed so that what a variable is and does can be determined by the way it is defined or used. Vensim ${ }^{\circ}$ has eleven variable types [40] and a few of them were used to develop the model for this study.

The model consists of interconnections of four different sectors in the subregion. The sectors, namely, electricity (split into capacity addition (MW), power demand (GWh)), demography (principally, the population) (persons), and economy as depicted by the gross

Table 6 LCD option parameters in the EP-LCD model

\begin{tabular}{|c|c|c|c|c|c|c|c|c|}
\hline & Fuel type & $\begin{array}{l}\text { Capacity } \\
\text { (MW) }\end{array}$ & $\begin{array}{l}\text { Capacity factor } \\
(\mathrm{Dmnl})\end{array}$ & $\begin{array}{l}\text { Capacity lifetime } \\
\text { (years) }\end{array}$ & $\begin{array}{l}\text { Construction } \\
\text { time (years) }\end{array}$ & $\begin{array}{l}\text { Emission factor, }{ }^{a, b} \\
\left(\mathrm{tCO}_{2} / \mathrm{MWh}\right)\end{array}$ & $\begin{array}{l}\text { Normal per capita } \\
\text { electricity demand } \\
\text { (MWh/person) }\end{array}$ & $\begin{array}{l}\text { Time to adjust } \\
\text { capacity (years) }\end{array}$ \\
\hline \multirow{6}{*}{$\begin{array}{l}\text { Grid } \\
\text { technologies }\end{array}$} & $\begin{array}{l}\text { Simple cycle } \\
\text { gas turbine }\end{array}$ & 1410 & 0.80 & 25 & 3 & $0.2786^{c}$ & \multirow[t]{11}{*}{0.546} & \multirow[t]{11}{*}{21} \\
\hline & $\begin{array}{l}\text { Combined cycle } \\
\text { gas turbine }\end{array}$ & 4892 & 0.80 & 25 & 3 & 0.2020 & & \\
\hline & Hydropower & 3760 & 0.80 & 50 & 10 & 0.0 & & \\
\hline & Coal subcritical & 32 & 0.80 & 25 & 8 & 0.3413 & & \\
\hline & Nuclear & 0 & 0 & 25 & 10 & 0 & & \\
\hline & Wind & 100 & & & & 0 & & \\
\hline \multirow{3}{*}{$\begin{array}{l}\text { Renewable grid } \\
\text { technologies }\end{array}$} & Solar & 10 & & & & 0 & & \\
\hline & Small hydro & 100 & & & & 0 & & \\
\hline & $\begin{array}{l}\text { Diesel } \\
\text { generators }\end{array}$ & 678.0 & & & & 0.2667 & & \\
\hline \multirow{2}{*}{$\begin{array}{l}\text { Off-grid } \\
\text { technologies }\end{array}$} & $\begin{array}{l}\text { Gasoline } \\
\text { generators }\end{array}$ & 847.6 & & & & 0.2496 & & \\
\hline & Gas turbines & 169.5 & & & & 0.2020 & & \\
\hline
\end{tabular}

Sources: author's estimation

${ }^{\text {a}}$ Thomas, Rolls and Tennant [59]

${ }^{\mathrm{b}}$ The emission factor is the ton of $\mathrm{CO}_{2}$ consumed per generation of $1 \mathrm{MWh}$ of electricity

${ }^{\mathrm{C}} \mathrm{A}$ review of other literatures $[60,61]$ aside from Thomas, Rolls and Tennant [59] show that the emission factors for gas turbines are the same. The study used that for combined cycle gas turbine to run the model 


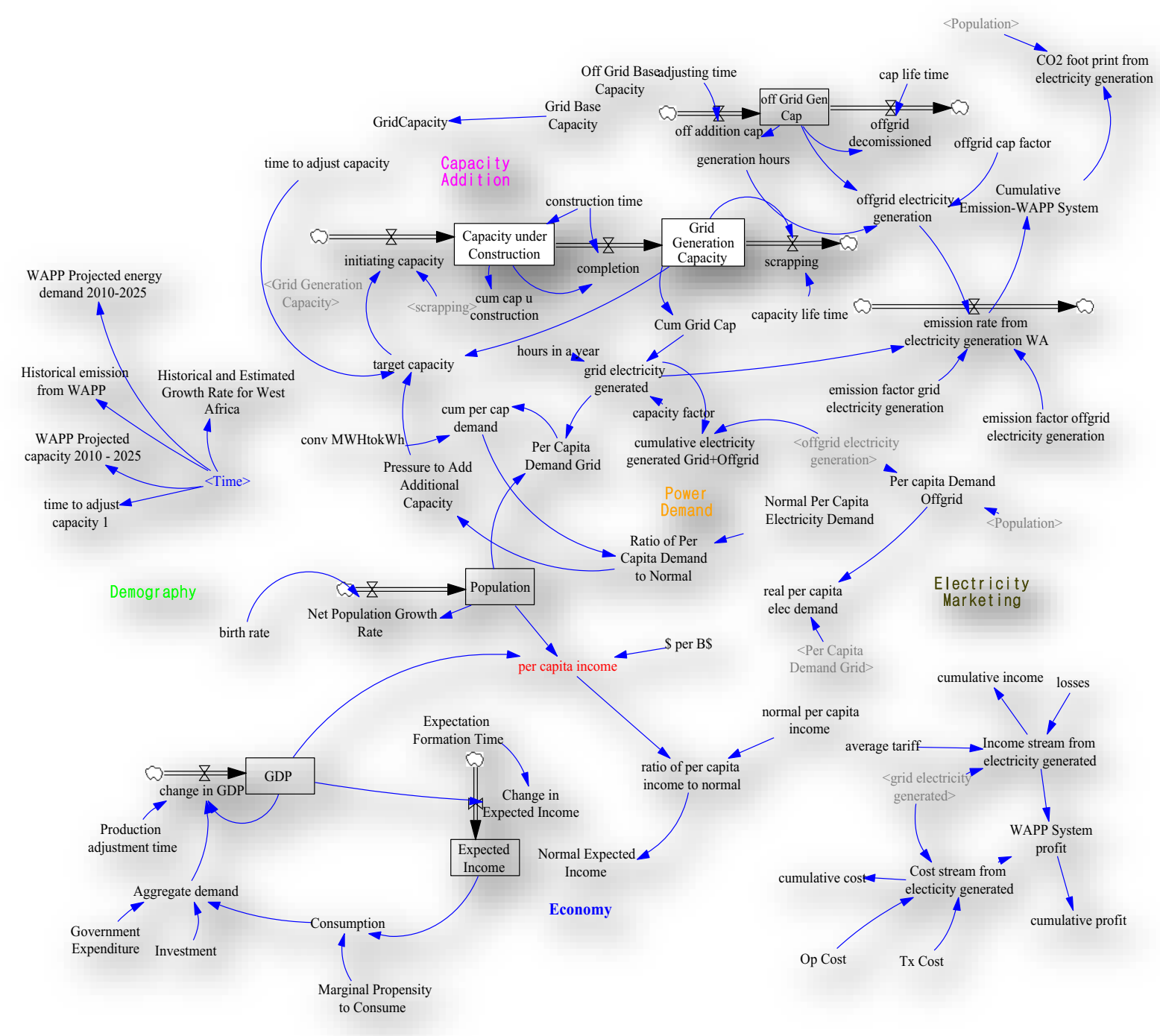

Fig. 6 Electricity Planning-Low-Carbon Development model

domestic product (GDP) (Billion USD), make up the four modules/segments in the model. Two other submodules/segments in the model are offshoot from power demand module/segment. These are emission from electricity consumption $\left(\mathrm{tCO}_{2}\right)$ and electricity marketing (USD). Each of the modules has at least one level variable with integral equation. The capacity addition module consists of both grid and off-grid capacity. The off-grid segment captures electricity consumption from self-generation. In the grid segment, capacity under construction was included to reflect how capacity is increased over the years. The grid capacity segment also has scrapping, which is driven principally by capacity life time (years). To guide the model development, combined cycle gas turbine (CCGT) was chosen as the representative ${ }^{3}$ technology. This was done based on its characteristics of fuel type, efficiency of operation, heat recovery system, and construction time. The critical aspect of the capacity under construction is the assessment of initiating capacity, which in turn is driven by target capacity (MW) and time to adjust (years). (In a fully liberalized market, this is expected to be determined by investor behavior-e.g., see [42]). The model effected adjustment to Grid Generating Capacity by inclusion of the variables target capacity and time to adjust capacity. Target capacity is capacity needed to be added from the four technologies in the existing stock based on expectations, while time to adjust capacity represents the time required to begin construction of new capacities as compared to the time to set in the model to retire any of the existing capacity as benchmarked using the representative technology. The target 
capacity initializes the initiating capacity which in turn affects the capacity under construction. The target capacity for the model was set on the basis of grid generation capacity. The target capacity is driven by per capita power demand in the system. The per capita power demand ( $\mathrm{kWh} /$ person) in the system is assumed to be driven principally by population (this is derived from the demography segment of the model). The individual target in the model was set based on their contribution to the existing stock and their capacity lifetime or decommissioning period. Capacity replacement is expected to commence based on how long construction will last to the time that the particular technology in the stock will be decommissioned. For instance, a new CCGT plant for replacement should commence construction at about 3 years prior to the decommissioning of an existing plant in the stock.

\section{Model output based on different scenarios}

The model was developed with subscripts. ${ }^{4}$ This allowed a variable (e.g., grid capacity, birth rate, and GDP) in the model to be represented by country distinctly. Levels (or state variables) define the dynamics of a system. Most level variable equations in Vensim ${ }^{\circ}$ software take the form of:

$$
\text { Level variable }(\text { name })=\int(\text { inflow }(t)-\text { outflow }(t), \text { initial_value }(0)
$$

Level variables represent stocks in System dynamics models. This means that all the level variables in the model, namely, population, GDP, capacity under construction, and grid generation capacity are stock operating the principle of accumulation, ${ }^{5}$ and take on the form of Eq. (1) to run in the model. The model was run in time space of 50 years, using 2011 as the base year and 2060 as the terminal year.

Comparison of the results from running the model at base case and LCD options respectively is discussed next. The base case parameters for the model are presented in Table 6. After model structure was established with model and unit checks made, it was further validated using values got for WAPP in another independent study [14] as presented in Table 7. These comparisons show the same projection pattern between 2011 and 2024 but different values. The values used in this study are real time values for between 2011 and 2014, while those for the independent study [14] were anticipated growth in capacity, electricity to be generated and the harmful gasses to be emitted to the atmosphere. Figure $7 \mathrm{a}-\mathrm{c}$ show the projected generation capacity, electricity generated, and emission from the energy/technology mix in the WAPP stock. As shown in Fig. 8, simulation result for the grid electricity generated shows similar pattern to that of an independent projected electricity demand for WAPP, while Fig. 9 shows scenario comparison of its grid capacity. Figure 10 presents the cumulative emission from generation of electricity in the WAPP system. Between 2011 and 2012, emission of harmful GHG to the atmosphere dropped as generation also dropped but began a steady rise for the simulation period to a value of 6.154 billion $\mathrm{tCO}_{2}$ in 2060 in LCD option scenario. The point being made with these comparisons is that growth is expected in the West African electricity system for its generation capacity and electricity demand, which in turn will cause increased emissions of harmful GHG to the atmosphere.

\section{Time to adjust capacity and expectation formation time}

At the test run, after the model structure was developed, two parameters were found to have considerable influence on the model behavior, namely, time to adjust capacity and expectation formation time. The first is directly related to capacity addition in generation and so was included in the Electricity Sphere, while the second is related to GDP and was included in the socialeconomic sphere. Literature is very scarce on the issue of time to adjust capacity, which is similar to expectation formation time, hence the brief explanation of these parameters. For time to adjust capacity, usually a number of steps are taken to manage the load in a grid system. This is known as load management or demand side management. This is simply the process of balancing the supply of electricity on the network with electrical load by adjusting or controlling the load rather than the power output. However, due to the fact that generators in the network will at a time or the other come to the

Table 7 Comparing results of WAPP study and that from this study

\begin{tabular}{|c|c|c|c|c|c|c|c|c|}
\hline \multirow[b]{2}{*}{ Result comparison } & \multicolumn{2}{|l|}{2011} & \multicolumn{2}{|l|}{2015} & \multicolumn{2}{|l|}{2020} & \multicolumn{2}{|l|}{2025} \\
\hline & WAPP (2014) & $\begin{array}{l}\text { This study } \\
\text { (LCD option } \\
\text { scenario) }\end{array}$ & WAPP (2014) & $\begin{array}{l}\text { This study } \\
\text { (LCD option } \\
\text { scenario) }\end{array}$ & WAPP (2014) & $\begin{array}{l}\text { This study } \\
\text { (LCD option } \\
\text { scenario) }\end{array}$ & WAPP (2014) & $\begin{array}{l}\text { This study } \\
\text { (LCD option } \\
\text { scenario) }\end{array}$ \\
\hline Capacity, (MW) & 10,609 & 10,094 & 17,371 & 10,109 & 24,109 & 14,768 & 31,728 & 22,178 \\
\hline Generation, GWh & 65,346 & 53,962 & 107,298 & 54,041 & 149,344 & 78,954 & 198,175 & 118,564 \\
\hline Emission, million $\mathrm{tCO}_{2}$ & 2120 & 90.16 & 2500 & 97.17 & - & 131.92 & - & 198 \\
\hline
\end{tabular}

Sources: WAPP (2014), this study 


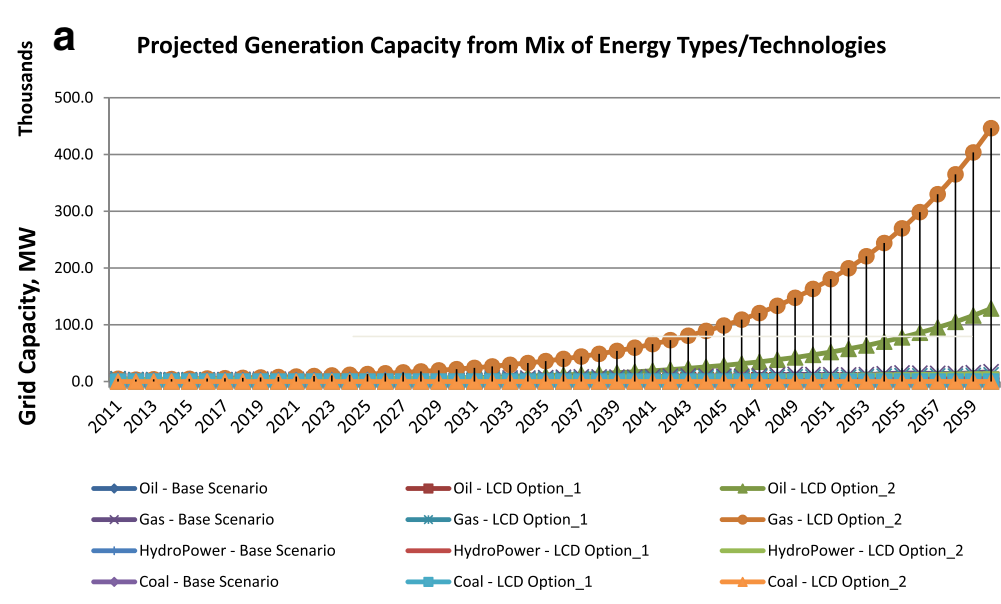

b Projected Energy Generated from Mix of Energy Types/Technologies

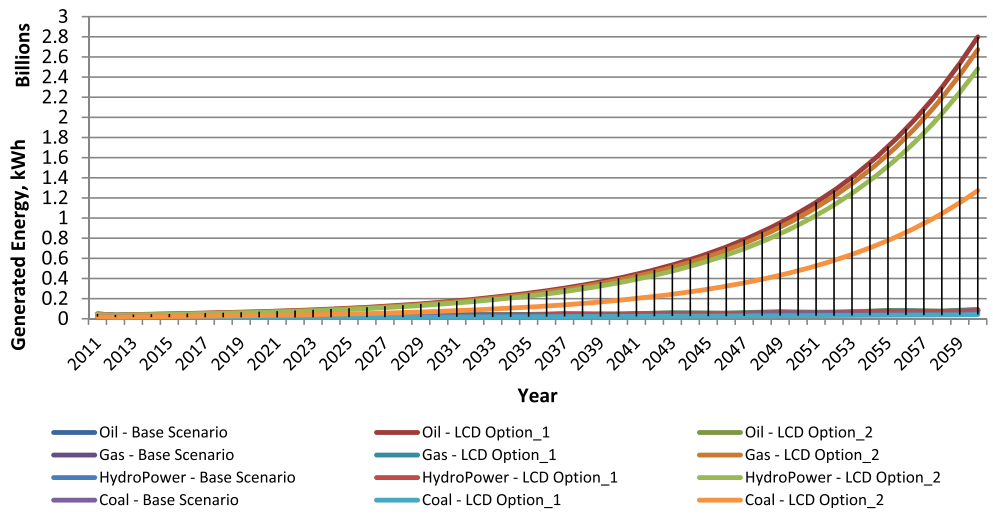

C Projected GHG Emission from Mix of Energy Types/Technologies

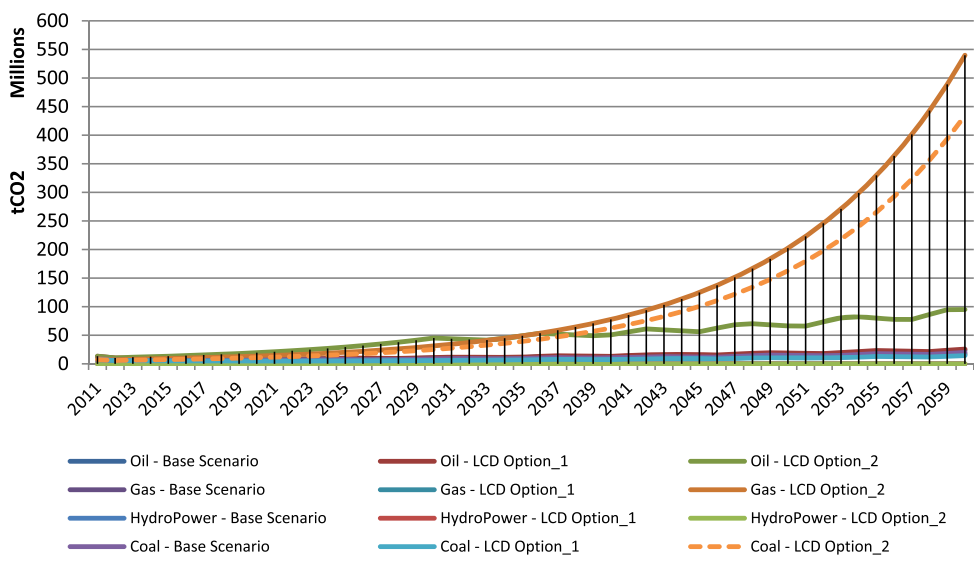

Fig. 7 a Projected generation capacity from mix of energy types/technologies from EP-LCD model. b Projected energy generated from mix of energy types/technologies from EP-LCD model. c Projected GHG emission from mix of energy types/technologies from EP-LCD model

end of their lifetime and be disengaged from service, it is critical to also determine the time to adjust capacity. Time to adjust capacity refers to the time in planning for generation capacity when new capacity must be planned for to be added to existing capacity to avoid overstretching the installed capacity. This is usually signaled by tight reserve margin. Reserve margin is what the electricity utility industry employs as a simple strategy for maintaining reliability, i.e., always have more supply available than may be required. Yet, it can be difficult to forecast future electricity demand, and building new generating capacity can take years. The industry 


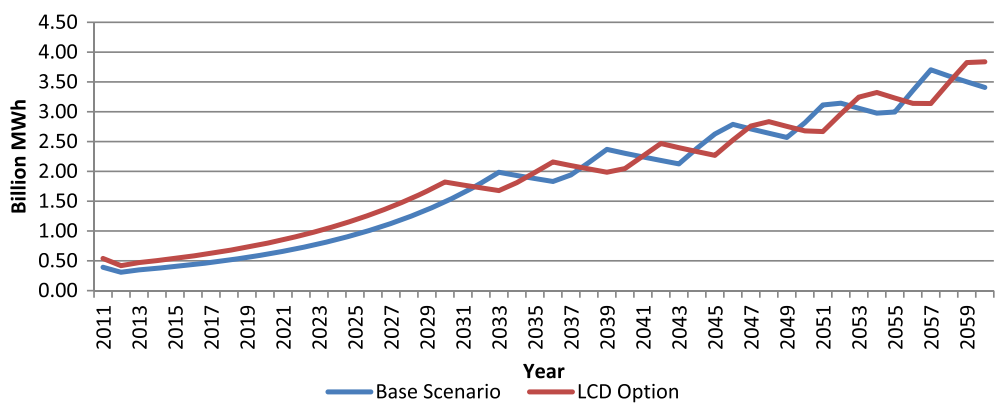

Fig. 8 Scenario comparison of electricity generated in the WAPP system

regularly monitors the supply situation using a measure called reserve margin. Reserve margin is (capacity minus demand)/demand, where "capacity" is the expected maximum available supply and "demand" is the expected peak demand. It is calculated for electric systems or regions made up of a number of electric systems. For instance, a reserve margin of $15 \%$ means that an electric system has excess capacity in the amount of $15 \%$ of expected peak demand [43].For this study, 20 years was chosen for the time to adjust capacity, deduced from the average time it will take for the construction of a combined cycle gas power plant (3 years) and an allowance of 2 years for delays.

Expectation is defined simply as the act or state of anticipating what would happen [44].So expectation formation represents the factors underlying the act or state of anticipation [45].According to EcoBank [46], "weak cost recovery has reduced the ability of state utilities to maintain plants and equipment, leaving little capital to expand or rehabilitate infrastructures, and opening up avenues for cheaply priced assets to be snapped up by an emerging private sector in many Sub Sahara African (SSA) markets." So, in this study, it was taken that to achieve investment decision to increase capacity in generation or investment in any of the segment in the WAPP electricity system, there would be assurance that there is enough certainty of cost recovery [44]. The value used for the base case scenario was 7.5 years. These options were adapted from economic cost recovery period defined in Multi-Year Tariff Order (MYTO) by the Nigeria Electricity Regulatory Commission [47].

Table 8 presents comparative result of cumulative generation capacity, cumulative electricity generated, and emissions from the generated activities simulated in the WAPP electricity system. As can be seen from the table, each of the variables dropped for the scenario with LCD option by 2060. Figure 9 presents simulated grid generation capacity in the WAPP electricity system. The figure shows decrease in generation capacity with the LCD option due to some factors: improved capacity factor due to improved generation technology efficiency which in turn produces less carbon dioxide and other GHG emissions from generation activities. The ultimate goal of a low-carbon development strategy is to achieve a lower level of emissions of GHG in the short and long term from electricity sector. Figure 10 presents the simulated emissions from generated activities in the WAPP electricity system. At 2059/60, it was observed that base case scenario had a higher emission than LCD option. Taking the analysis further, when comparing the simulation results to meet future demands as well as the attending emissions in the scenarios, there was marked difference. In terms of grid capacity, the simulation shows an annual increase of about 5\% for LCD option and 6\% for base case between 2011 and 2020; this increased to about 13 and $15 \%$, respectively, from 2020 to 2030 ; about 15 and $17 \%$ in 2030 to 2040 , about 16

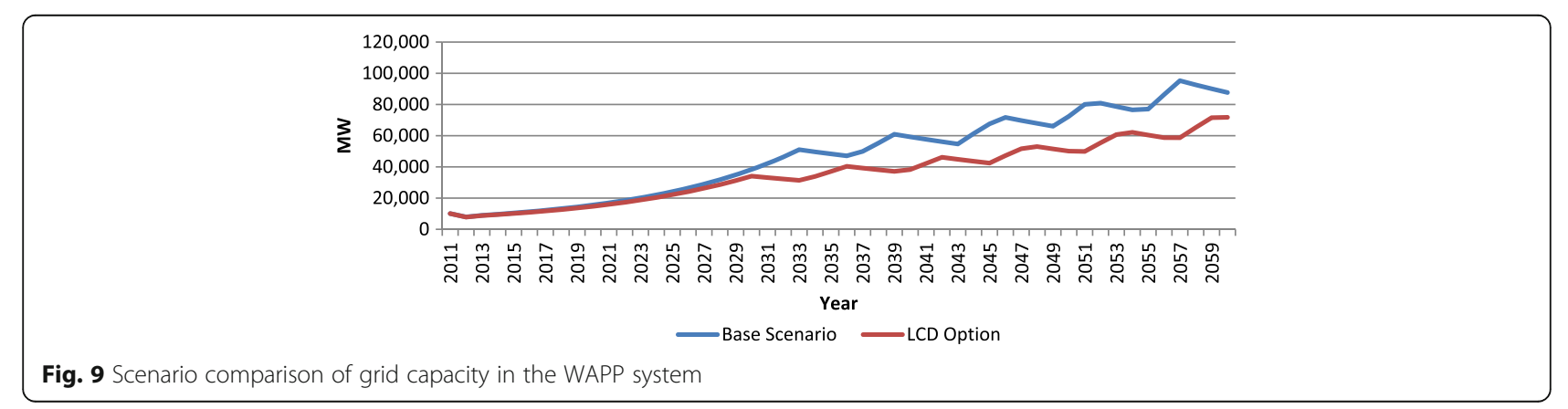




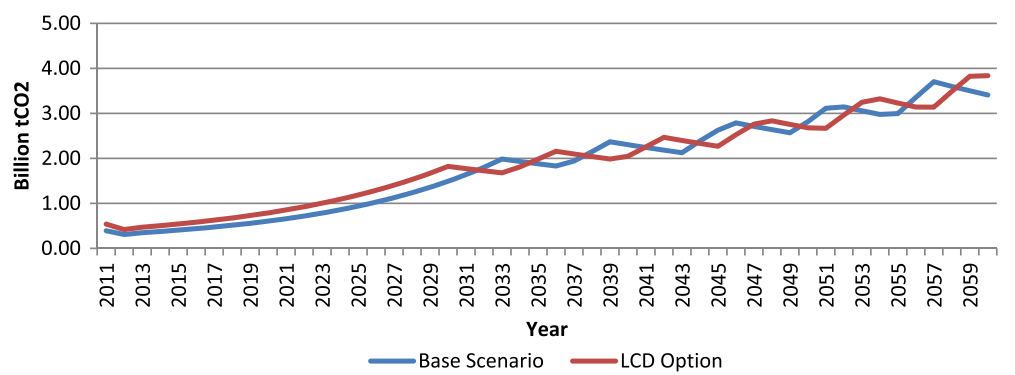

Fig. 10 Scenario comparison of cumulative emission from electricity generation in WAPP system

and $18 \%$ from 2040 to 2050 and through 2050 to 2060 , the average annual increment was about 17 and $19 \%$, respectively. For the base scenario, the increment needed where a little higher in each of the decades that were examined. The implications of these results (Table 8, Figs. 9 and 10) demonstrate the kind of effect that the identified high leverage points could have on the system in terms of policy shift in the long term $[48,49]$. Importantly, high leverage points located (CF, EF, time to adjust capacity, and expectation formation) in this study will help to situate relevant intervention policies for enhancing the environmental footprint from electricity production in the system. The model's principal contribution then will be to eliminate the usual trial and error approach that characterizes policy formulation, which are usually costly and time-consuming.

To demonstrate the model's robustness, sensitivity testing was conducted on it. This involves the process of changing the assumptions about the value of constants in the model and examining the resulting output. Monte Carlo simulation, also known as multivariate sensitivity simulation (MVSS), was used on the LCD option scenario in understanding the behavioral boundaries of its maximum and minimum values respectively using the parameters presented in Table 8. Gas was taking as the representative fuel and combined cycle gas turbine (CCGT) as the representative technology. The values selected were done arbitrarily to test if there would be

Table 8 Ranges of future electricity generation, $\mathrm{CO}_{2}$ emissions, and some basic assumptions

\begin{tabular}{|c|c|c|c|c|c|}
\hline Description & Scenario & 2011 & 2036 & 2060 & Remark \\
\hline \multirow[t]{4}{*}{ Electricity generated, billion MWh } & \multirow{2}{*}{$\begin{array}{l}\text { Base; } 1 \\
\text { LCD option; } 1\end{array}$} & 0.3925 & 0.5427 & 1.053 & \multirow{2}{*}{$\begin{array}{l}\text { Electricity generated at base scenario was } \\
\text { higher than the LCD option by about } 1 \%\end{array}$} \\
\hline & & 0.5392 & 0.5315 & 1.043 & \\
\hline & \multirow{2}{*}{$\begin{array}{l}\text { Base; } 2 \\
\text { LCD option; } 2\end{array}$} & 0.3925 & 1.831 & 3.408 & \multirow{2}{*}{$\begin{array}{l}\text { Electricity generated at LCD option scenario } \\
\text { was higher than the base option by about } \\
12.61 \%\end{array}$} \\
\hline & & 0.5392 & 2.158 & 3.838 & \\
\hline \multirow[t]{4}{*}{$\mathrm{CO}_{2}$ emission, million $\mathrm{tCO}_{2}$} & \multirow{2}{*}{$\begin{array}{l}\text { Base; } 1 \\
\text { LCD option; } 1\end{array}$} & 66.58 & 92.07 & 178.7 & \multirow{2}{*}{$\begin{array}{l}\text { Emission from the base scenario shows a } \\
\text { difference of about } 2.5 \% \text { to that of } L C D \text { option }\end{array}$} \\
\hline & & 90.16 & 88.8 & 174.3 & \\
\hline & \multirow{2}{*}{$\begin{array}{l}\text { Base; } 2 \\
\text { LCD option; } 2\end{array}$} & 66.58 & 310.6 & 578.3 & \multirow{2}{*}{$\begin{array}{l}\text { Emission from the LCD option was higher by } \\
\text { about } 11 \% \text { to that of base scenario }\end{array}$} \\
\hline & & 90.16 & 360.6 & 641.2 & \\
\hline \multicolumn{6}{|l|}{ Assumptions } \\
\hline \multirow{4}{*}{$\begin{array}{l}\text { Per capita electricity consumption, } \\
\text { MWh/cap }\end{array}$} & \multirow{2}{*}{$\begin{array}{l}\text { Base; } 1 \\
\text { Base; } 2\end{array}$} & 0.146 & & & \multirow[t]{4}{*}{ Reference year; 2011} \\
\hline & & 0.546 & & & \\
\hline & \multirow{2}{*}{$\begin{array}{l}\text { LCD option; } 1 \\
\text { LCD option; } 2\end{array}$} & 0.146 & & & \\
\hline & & 0.546 & & & \\
\hline Representative technology & All scenarios & CCGT & & & \\
\hline \multirow[t]{2}{*}{ Capacity factor, ratio } & Base; $1 \& 2$ & 0.48 & & & \multirow[t]{2}{*}{ Reference year; 2011} \\
\hline & LCD option; 1 \& 2 & 0.70 & & & \\
\hline \multicolumn{2}{|l|}{ Emission factor, $\mathrm{tCO}_{2} / \mathrm{MWh}$} & \multicolumn{3}{|c|}{0.2020 (held constant for all scenarios) } & \\
\hline \multirow[t]{2}{*}{ Expectation formation, years } & Base & 7.5 & & & \\
\hline & LCD option & 7.0 & & & \\
\hline \multirow[t]{2}{*}{ Time to adjust capacity, years } & Base & 21 & & & \\
\hline & LCD option & 20 & & & \\
\hline
\end{tabular}


difference in the outcome of each scenario option. Some assumptions made projected some ranges of future electricity generation and $\mathrm{CO}_{2}$ emissions. The model was run for two boundaries of per capita electricity consumption at the current average rate of $146 \mathrm{kWh} / \mathrm{cap}$ and a modestly increased value to $546 \mathrm{kWh} / \mathrm{cap}$. The maximum and minimum boundaries could be adjusted as desired. Other assumptions were that the capacity factor improved from 0.48 to 0.70 , expectation formation and time to adjust capacity were changed slightly and the emission factor was held constant. Sensitivity graph generated showing confidence bounds of five of the variables in the model, namely, cumulative target capacity, grid capacity, cumulative electricity generated, cumulative emission, and $\mathrm{CO}_{2}$ footprint, when the three parameters were randomly varied about their distributions, is shown in Fig. 11a-c and Table 9 respectively. The outer bounds of uncertainty (gray color in graph-100\%) show maximum values and inner bounds (yellow color-50\%) minimum values, respectively, at the end of the simulation. The results indicate that time to adjust capacity is the most significant parameter affecting capacity addition. Expectation formation time was reduced to 7 years.

\section{Lessons learnt from the model simulation and policy implications in the West African electricity system}

In System dynamics modeling, dynamic behavior is thought to arise due to the Principle of Accumulation $[35,50]$. This principle states that all dynamic behavior in the world occurs when flows accumulate in stocks, and this is crucial in determining the dynamic behavior of model developed to examine the West African

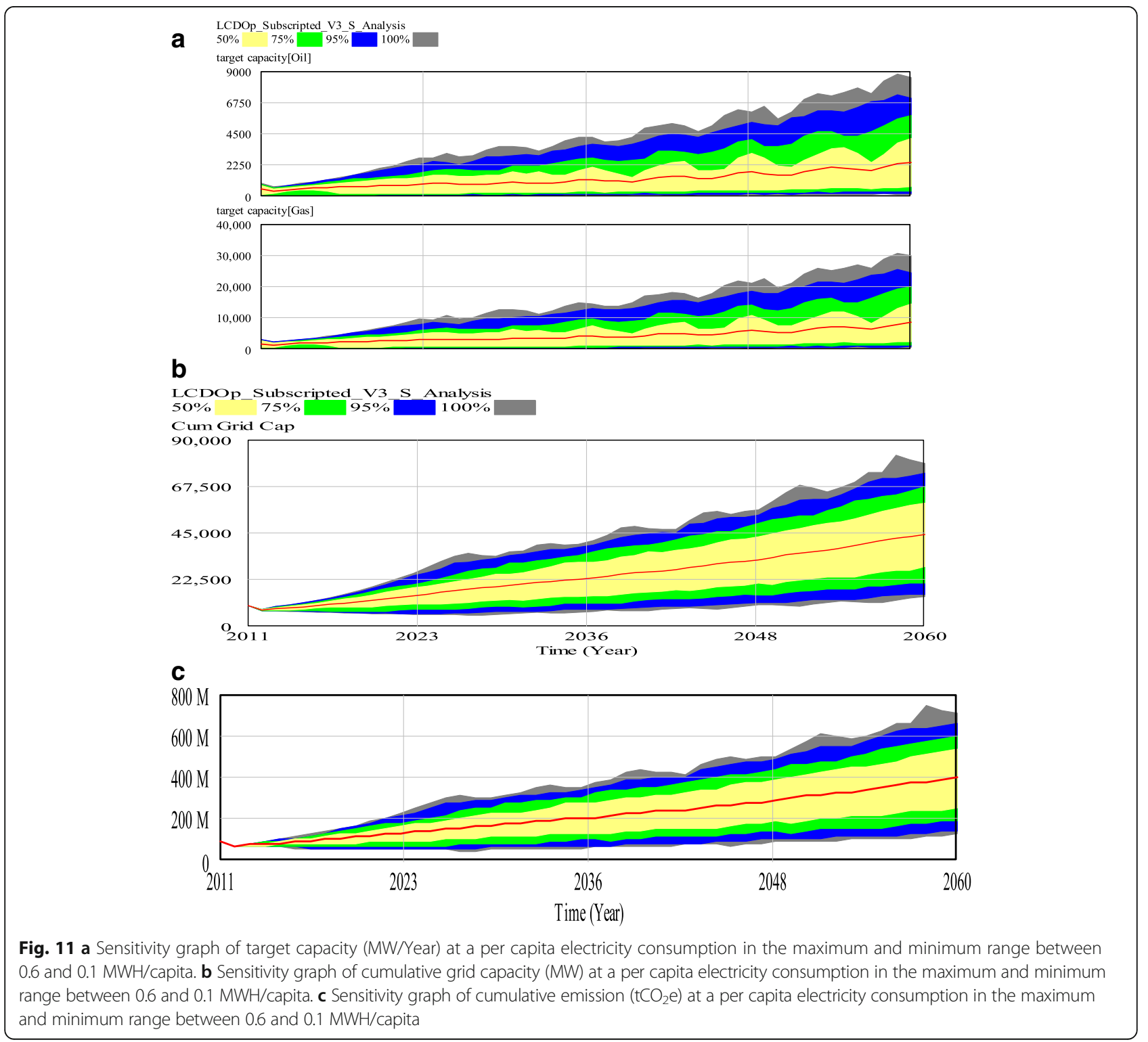


Table 9 Cumulative generation capacity (MW), electricity generated (MWh) and emission ( $\left.\mathrm{CCO}_{2}\right)$ (base case and LCD option)

\begin{tabular}{|c|c|c|c|c|c|c|}
\hline Time (year) & 2011 & 2020 & 2030 & 2040 & 2050 & 2060 \\
\hline \multicolumn{7}{|c|}{ Simulated cumulative grid capacity, MW } \\
\hline LCD option & $10,094.0$ & $14,768.8$ & $34,086.8$ & $84,834.5$ & $220,845.1$ & $589,107.6$ \\
\hline Base case & $10,094.0$ & $15,605.1$ & $38,329.0$ & $101,911.7$ & $283,509.6$ & $807,397.5$ \\
\hline \multicolumn{7}{|c|}{ Simulated cumulative electricity demand, kWh/person } \\
\hline LCD option & 603.6 & 694.9 & 1228.7 & 2342.7 & 4672.3 & 9548.5 \\
\hline Base case & 603.6 & 734.2 & 1381.6 & 2814.3 & 5998.1 & $13,086.6$ \\
\hline \multicolumn{7}{|c|}{ Simulated cumulative electricity generated, MWh } \\
\hline LCD option & $539,625,216$ & $789,540,608$ & $1,822,278,656$ & $4,535,250,944$ & $11,806,379,008$ & $31,493,689,344$ \\
\hline Base case & $392,454,720$ & $606,726,400$ & $1,490,232,064$ & $3,962,328,320$ & $11,022,852,096$ & $31,391,614,976$ \\
\hline \multicolumn{7}{|c|}{ Simulated cumulative emission from WAPP system, million $\mathrm{tCO}_{2}$} \\
\hline LCD option & 90.2 & 131.9 & 304.5 & 757.8 & 1972.6 & 5262.0 \\
\hline Base case & 66.6 & 102.9 & 252.8 & 672.3 & 1870.2 & 5326.0 \\
\hline
\end{tabular}

electricity system. The history of West African electricity system is that it has problem of inadequate electricity generation. This the model noted has accumulated over a period of time. So a change in the inflow side (supply technologies) to the stock (grid generation capacity) will not immediately lead to a decrease in inadequacy of generation supply in the stock; hence, it is important to pursue low-carbon development strategy to achieve reduced emission in excess of increased electricity capacity. The importance of this characteristic is that policy makers should realize that curing the problem of electricity inadequacy in the subregion and at the same time achieving low-carbon economy will require tradeoffs of inflow (development) and outflow (emission reduction) to achieve a balance in stock (grid generation capacity and power demand). Secondly, it must be recognized that grid capacity increase involves delays. Bergson [51] states that, "time is a device that prevents everything from happening at once." Thus, the significant lag between cause and effect called delay should also be taken into consideration in planning as the longer the delay between cause and effect, the more likely it is that a decision maker will not perceive a connection between the two. Essentially, a delay modifies the time relationship between the inflow and outflow delay structure [35]. Applying this explanation to the system examined, it follows that achieving increased grid capacity runs counter to the desire to reduce GHG emissions from the electricity sector. This makes achieving needed trade-offs between development policy and climate policy somewhat difficult. To achieve this trade-off, policy formulation will have to take cognizance of the existence of negative feedback loops. For instance, increased emissions result from increased business-as-usual generation technologies. So to increase supply of electricity without increasing emissions, there is the need to introduce lowcarbon development strategy through deliberate policy direction that encourages low emission technologies. Such policies as increasing per capita electricity generation to achieve poverty alleviation versus reducing per capita emission through mitigation and adaptation strategies need closer examination. The essence of this exercise is to guide the setting of mitigation targets for planning generation capacity addition in the West Africa electricity system.

The report by KPMG [52] indicates that power system in Africa, including West Africa, is characterized by aging power infrastructure that is unable to meet current power demands, underutilization of generation capacity due to low maintenance of assets, high primary energy costs and securing resources at reasonable prices to fuel current and build new assets among other challenges. This is in contrast to the Western Power Market, where each step of the energy value chain of electricity system is fully developed. In Sub-Saharan Africa, each step is at different development stage. Generation and transmission are the most developed, followed by distribution and retail, which are mainly coupled, and the development of an electricity trading sector has just started. Thus, the results of simulation from the model run present potential policy options that could be introduced to address the issues of overcoming poverty and achieving low carbon emissions through the West African electricity system. These could be done as stand-alone approaches or in combinations. The three policy options are fastened to improvement in the stock of technology to be introduced into the Generation Park, energy resource mix and financial instrument. The first and second options, which are within government/regulatory and investors purview, will deal with aging asset and maintenance issues. The third option is more of interest to investors as it deals with cost recovery of investments. These options were each represented in the model as technology (capacity factor (CF), emission factor (EF), and time to adjust capacity), energy resource mix (hydro, 
oil, nuclear, gas, and green energy), and financial instrument (cost recovery time or expectation formation). For example, the average $\mathrm{CF}$ for most of the existing generating power plants in the system is 0.48 . Policy in form of regulatory and financial instrument would be required for strict enforcement to maintain CF and EF in the system at a level far higher than what is currently obtained [see for example 50]. West African system currently has only four electricity technology types based on fuel used in its generation stock as shown in Table 5. Within these fuel types, there are variants. The current composition as of 2015 shows that oil contributes about $14 \%$, coal, $0.3 \%$, natural gas, $48.5 \%$ while hydro makes up the rest with $37.2 \%$. Nuclear is currently not among the mix of generation technologies. As indicated from the model sensitivity analysis, future investment in the West African electricity system will do well to take the time to adjust capacity into consideration with an expectation formation period of 7 years. It will also support generation technology, as ranked in Table 10, which combines improved CF with efficiency from low EF to achieve LCD strategy without compromising development [53]. This proposed policy shift, which has to be met with new and innovative technologies and dynamics in the infrastructure system as against the traditional practices and mixes, is called "disruption" [54]. It presents obvious trade-offs that entail change in technology types, generation practices, landscape of players and stakeholders, modes of business, methods of operations and systems, funding channels and models, among other.

Table 10 shows the ranking of the generating technology based on the fuels being used in the stock currently. This ranking was based on target capacity as depicted in Fig. 11a. The figure shows that target capacity for addition was highest for gas, followed by oil, then hydropower with the least being coal. This was unexpected though. Their initiating capacities are respectively 4892, 1410, 3760, and $32 \mathrm{MW}$. The parameter in the model that most likely affected the ranking is the construction time. Outside of the model, examining average generating efficiencies, average capacity factors, and emission factors of existing technologies in the West African electricity system gave a different ranking. The weighted average generating efficiency in 2011 was 35\% for coal,
$48 \%$ for natural gas, and $40 \%$ for oil-fired [55], while it was $95 \%$ for hydropower plants [56, 57]. The weighted average capacity factor in 2012 for the same generating technologies was $39 \%$ for hydro, $56 \%$ for coal, $38 \%$ for natural gas, and $36 \%$ for oil [58]. A comparison of these rankings as depicted in Table 10 went further to magnify the importance of developing the SD model for informed policy formulations for the electricity system or any system in the West African region. It need be stated that nuclear generating technology was not considered for any ranking.

\section{Discussions}

This paper discussed the trade-offs between electricity development, which is needed for economic growth, and its effect on climate change, if evidenced-based policies are to be provided. In this context, the SD model developed explored low-carbon development (LCD) pathways - with electricity at the heart of the trajectory. It recognises that whilst large-scale economic development is needed to pull millions of citizens out of abject poverty, business-as-usual approach would exacerbate climate change problem with potentially irreversible long-term consequences. The analysis involved formulation and simulation of spheres and sectors linked to the electric system to form complex link of feedback. These were analyzed and weighted as they could drive or limit LCD agenda.

\section{Conclusions}

The central focus of this preliminary assessment was to develop a System dynamics model for assessing the WAPP electricity system behavior in a low-carbon economy. Its principal aim is to eliminate the usual trial and error approach that characterizes policy formulation, which are usually costly and time-consuming The developed model-Electricity Planning-Low-Carbon Development (EP-LCD)-consists of the following modules: socio-economic, electricity, and LCD option. The socioeconomic module consists of variables and parameters on population and GDP; the electricity module has electricity marketing, capacity addition, power demand, and LCD option has $\mathrm{CO}_{2}$ emission estimation from electricity generation activities. For this study, the most critical sector is the capacity addition, which was linked to

Table 10 Ranking of technology options for West African electricity system in low-carbon development strategy

\begin{tabular}{lllllc}
\hline Generation/fuel type & $\begin{array}{l}\text { Ranking from model } \\
\text { using target capacity }\end{array}$ & $\begin{array}{l}\text { Weighted average } \\
\text { capacity factor, \% }\end{array}$ & $\begin{array}{l}\text { Weighted average } \\
\text { generating efficiency, \% }\end{array}$ & $\begin{array}{l}\text { Emission factor } \\
\left(\mathrm{tCO}_{2} / \mathrm{MWh}^{2}\right.\end{array}$ & $\begin{array}{c}\text { Other ranking } \\
\text { Natural gas }\end{array}$ \\
\hline & 38 & 48 & 95 & 0.2020 & 1 \\
Oil & 2 & 39 & 35 & 0.0 & 4 \\
Hydro & 3 & 56 & 40 & 0.3413 & 2 \\
Coal & 4 & 36 & & 0.2786 & 3 \\
\hline
\end{tabular}


emission assessment from electricity generated in the system. Also incorporated into the model is offgrid $^{6}$ generation to capture how suppressed demand is being met in the subregion.

The structure of the model was first established to ascertain the model behavior, this was followed by unit checks; the model has also been calibrated using values for the parameters identified in the model by means of data from WAPP and the high leverage points identified. Sensitivity analysis was conducted to bring out important conclusions and inferences. However, the model development is still work in progress to include the transportation sector into it and would need further validation especially concerning the economy sector. Comparing results of the two scenarios: base case and LCD option revealed the high leverage points in the model. These are capacity factor, adjustment time for capacity, expectation formation, and emission factor. The first three are directly or indirectly relevant to capacity addition and electricity generated while the last one has relevance with emission. These are variables within the West African electricity system that are small (i.e., requiring an improved adjustment of less than or equal to $10 \%$ margin of their existing value) yet could produce desired low-carbon emission as identified in the simulation and help to situate firming intervention policy to reduce environmental footprint from electricity production. Further, the SD model could help to eliminate the trial and error approach to policy formulation, which are usually costly and time-consuming. The simulation results identified three low hanging policy options, namely, improvement in the stock of generation park technology, energy resource mix and financial instrument. Also, the system analysis approach showed all variables to be interrelated in the model and is useful to enable the achievement of low-carbon development strategy for the WAPP electricity system. It should be pointed out that though wind and solar power generation were included in the model development, they do not reflect in the results due to paucity of data as regards their development in the subregion. The same limitation applies for the use of CCGT in this study as a representative generation technology and one constant for the capacity factor. Data improvement from these parameters will not only bring out their contribution in the electricity system but will also improve results as designed in the model.

In concluding this paper, the authors paraphrased from Abbas [13] that it is important to note that the ultimate aim of developing SD model is to aid policy makers in reaching optimum policy design. Thus, its validity should therefore be viewed from the perspective of the "model usefulness" rather than from its "numerical exactness" [13].

\section{Endnotes}

${ }^{1}$ Due to paucity of data, this value was adopted from the study financed by UK Official Development Assistance (UK ODA), a London Economics team in 1991 prepared a least-cost expansion plan for the National Electric Power Authority (NEPA) system through the year 2011 for the West African subregion.

${ }^{2}$ Enunciated in WAPP Business Plan - 2012-2015.

${ }^{3}$ The concept of representative technology using CCGT was taken based on the fact that the technology is the most favored technology to replace aging power plants in the existing stock. Secondly, it is seen as the easiest technology to be deployed when compared to others in the current stock.

${ }^{4}$ Subscripts allow a single variable to represent more than one thing. Subscripts do not appear in sketches. Sketches represent structure, and subscripts are a convenient way of replicating structure. The sketch maintains a simpler and less cluttered view of a model by not distinguishing subscripted and unsubscripted variables.

${ }^{5}$ Accumulate: growing or increasing over time (source [44]).

${ }^{6}$ Off-grid generation is got from diesel and gasoline generators as well as gas turbines (World Bank 2013).

\section{Abbreviations}

ABM: Agent-based modeling; CCGT: Combined cycle gas turbine; CLD: Causal loop diagram; COP: Conference of parties; ECOWAS: Economic Community of West Africa States; ECREEE: ECOWAS centre for renewable energy and energy efficiency; EP-LCD: Electricity Planning-Low-Carbon Development; ERERA: ECOWAS Regional Regulatory Authority; GDP: Gross Domestic Product; GHG: Greenhouse gas; GWh: Gigawatt hour; INDCs: Intended Nationally Determined Contributions; IPCC: Intergovernmental Panel for Climate Change; kWh: Kilowatt hour; LCD(S): Low-Carbon Development (strategy); MVSS: Multivariate sensitivity simulation; MW: Megawatts; MYTO: Multi-Year Tariff Order; SD: System dynamics; SFD: Stock-flow diagram; SSA: Sub-Saharan Africa; UNFCCC: United Nations Framework Convention on Climate Change; USD: United State dollars; WAPP: West African Power Pool

\section{Acknowledgements \\ This research is supported by funding from the Department for International Development (DfID) under the Climate Impact Research Capacity and Leadership Enhancement (CIRCLE) programme. It was conducted at The Energy Centre, College of Engineering, Kwame Nkrumah University of Science and Technology (KNUST), Kumasi, Ghana. The contribution of Tom Fiddaman in developing the model for this study is also gratefully acknowledged. The authors are most grateful to three anonymous reviewers.}

\section{Authors' contributions}

The individual contributions of authors to the manuscript are as follows: ASM made substantial contribution to the conception and design, acquisition of data, data analysis, interpretation of data, gave final approval of the version to be published, and agreed to be accountable for all aspects of the work. AA made contribution to the conception and design, acquisition of data, gave final approval of the version to be published, and agreed to be accountable for all aspects of the work. JKA made substantial contribution to the conception and design, gave final approval of the version to be published, and agreed to be accountable for all aspects of the work. YM made substantial contribution to the conception and design, gave final approval of the version to be published, and agreed to be accountable for all aspects of the work. 


\section{Publisher's Note}

Springer Nature remains neutral with regard to jurisdictional claims in published maps and institutional affiliations.

\section{Author details}

'Obafemi Awolowo University, Ile-Ife, Nigeria. ${ }^{2}$ CIRCLE Postdoctoral Visiting Fellow, The Energy Centre, College of Engineering, Kwame Nkrumah University of Science and Technology, Kumasi, Ghana. ${ }^{3}$ The Energy Center, College of Engineering, Kwame Nkrumah University of Science and Technology, Kumasi, Ghana. ${ }^{4}$ Department of Science, Technology, Engineering and Public Policy (STEaPP), University College London, Boston House, London W1T 6EY, UK.

Received: 10 October 2016 Accepted: 18 March 2017

Published online: 25 April 2017

\section{References}

1. UNEP (2011) Low carbon development strategies: a primer on framing nationally appropriate mitigation actions (NAMAs) in developing countries. http://www.namapipeline.org/Publications/

LowCarbonDevelopmentStrategies_NAMAprimer.pdf. Accessed 7 Jul 2014

2. Cervigni R, Rogers JA, Henrion M, eds. (2013). Low-Carbon Development: Opportunities for Nigeria. Directions in Development. World Bank, Washington. doi:10.1596/978-0-8213-9925-5. License: Creative Commons Attribution CC BY 3.0 on 10 July 2015

3. Momodu AS (2012) Evaluation of long term performance of electric power system in Nigeria. Ph.D. Thesis, Obafemi Awolowo University, lle-lfe, Nigeria

4. Olsina F, Garcés F, Haubrich HJ (2006) Modeling long-term dynamics of electricity markets. Energy Policy 34(12):1411-1433

5. UN (1987) Report of the World Commission on Environment and Development: Our Common Future. Retrieved from www.un-documents. net/wced-ocf.htm on March 182015

6. World Bank (2015) Population growth (annual \%). data.worldbank.org/ indicator/SP.POP.GROW. Accessed 14 Jun 2015

7. IPCC, 2014: Climate Change 2014: Synthesis Report. Contribution of Working Groups I, II and III to the Fifth Assessment Report of the Intergovernmental Panel on Climate Change [Core Writing Team, R.K. Pachauri and L.A. Meyer (eds.)]. IPCC, Geneva, Switzerland, 151 pp.

8. Gupta S, Tirpak DA, Burger N, Gupta J, Höhne N, Boncheva Al, Kanoan GM, Kolstad C, Kruger JA, Michaelowa A, Murase S, Pershing J, Saijo T, Sari A (2007) Policies, instruments and co-operative arrangements. In: Metz B, Davidson OR, Bosch PR, Dave R, Meyer LA (eds) Climate Change 2007: Mitigation. Contribution of Working Group III to the Fourth Assessment Report of the Intergovernmental Panel on Climate Change. Cambridge University Press, Cambridge

9. Amazon Environmental Research Institute (IPAM), 2014. Stimulating the demand for REDD+ emission reductions in Brazil: The need for a strategic intervention pre 2020: a case study for the Interim Forest Finance Project. Written by the Amazon Environmental Research Institute (IPAM), Brasilia, Brazil. Published by Global Canopy Programme, Oxford, UK.

10. Schneider SH (1989) The greenhouse effect: Science and policy. Science 243:771-781

11. Olsina F (2005) Long-term dynamics of liberalized electricity markets. Ph.D. thesis submitted to Department of Postgraduate Studies, Faculty of Engineering, National University of San Juan, San Juan. Retrieved from hrudnick.sitios.ing.uc.cl/paperspdf/Olsina.pdf. Accessed 8 Sept 2008

12. Ford A (1997) System dynamics and the electric power industry. Jay Wright Forrester Prize Lecture, 1996 - System Dynamics Review Vol. 13, No. 1, (Spring 1997): 57-85. Published by John Wiley \& Sons, Ltd. CCC 0883-7066/97/010057-29

13. Abbas KA (1990) The use of System dynamics in modelling transportation systems with respect to new cities in Egypt. System 90:17

14. Tractebel Engineering (2011) Update of the ECOWAS Revised Master Plan for the generation and transmission of electrical energy Final Report Volume 1: study data. Report prepared for WAPP Secretariat, Cotonou, Benin Republic

15. WAPP (2014) Feasibility study for development of a regional grid emission factor for the West African Power Pool (WAPP) as a standardised baseline. Report prepared by Climate Focus in partnership with Ecosur Afrique for the West African Power Pool

16. Levin K, Rich D, Bonduki Y, Comstock M, Tirpak D, Mcgray H, Noble I, Mogelgaard K, Waskow D (2015) Designing and preparing intended nationally determined contributions (INDCs). World Resources Institute and UNDP, Available at http://www.wri.org/publication/designingandpreparing-indcs

17. Hedger M, Smita NO (2015) Finance and intended nationally determined contributions (INDCs): enabling implementation. https://www.odi.org/sites/ odi.org.uk/files/odi-assets/publications-opinion-files/9909.pdf. Accessed 10 Jun 2016

18. ESMAP (2009) Low carbon growth country studies-getting started: experience from six countries. http://sdwebx.worldbank.org/climateportalb/ doc/ESMAP/KnowledgeProducts/Low_Carbon_Growth_Country_Studies_ Getting_Started.pdf. Accessed 1 Jul 2013

19. Hertzmark D (2007) Risk assessment methods for power utility planning. Special Report 001/007 Energy Sector Management Assistance, The International Bank for Reconstruction and Development/THE WORLD BANK

20. Vits H, Navarro LF. and Chavarria RE (2007) Siamese Twins: the gas and electric sectors in Bolivia. Technical paper published in the Rio Pipeline Conference\& Exposition 2007 Annals

21. Mirzaesmaeeli H (2007) A multi-period optimization model for energy planning with carbon dioxide emission consideration. University of Waterloo, Canada

22. Ventosa M, Balıllo A, Ramos A, Rivier M (2005) Electricity market modeling trends. Energy Policy 33(2005):897-913

23. Biswas S, Narahari Y (2003) Object oriented modeling and decision support for supply chains. Eur J Oper Res 153(3):704-726

24. Lo KL, McDonald JR, Le TQ (1991) Time-of-day electricity pricing incorporating elasticity of load management purposes. Int J Electr Power Energy Syst 13(4):230-239

25. Chern WS, Just RE (1982) Assessing the need for power: a regional econometric model. Energy Econ 4(4):232-239

26. Bunn DW, Larsen ER (1997) Systems modelling for energy policy. John Wiley \& Sons Ltd., UK

27. Ford A (2001) Waiting for the boom: a simulation study of power plant construction in California. Energy Policy 29(11):847-869

28. Macal CM and North MJ (2006) Tutorial on agent-based modeling and simulation part 2: how to model with agents. In L. F. Perrone, F. P. Wieland, J. Liu, B. G. Lawson, D. M. Nicol, and R. M. Fujimoto, eds. Proceedings of the 2006 Winter Simulation Conference

29. Borschev A and Filipov A (2004) From System dynamics and discrete event to practical agent-based modelling: reasons, techniques and tools. Proceedings of System Dynamics Conference, Oxford

30. Pourdehnad J, Maani K, \& Sedehi H (2002) System dynamics and intelligent agent-based simulation: where is the synergy. In Proceedings of the XX International Conference of the System Dynamics society

31. Scholl H (2001) Agent-based and System dynamics modelling: a call for cross study and joint research. Proceedings of the 34th Hawaii International Conference on System Sciences

32. Kilanc PG, Or I (2008) A decision support tool for the analysis of pricing, investment and regulatory processes in a decentralized electricity market. Energy Policy 36(2008):3036-3044

33. Johnson RA, Wichern DW (1997) Business statistics: decision making with data. John Wiley \& Sons, Inc., The United States of America

34. Zagonel AA, Corbet TF (2006) Levels of confidence in System dynamics modeling: a pragmatic approach to assessment of dynamic models. 24th International Conference of the System Dynamics Society. Nijmegen, The Netherlands. http://www.systemdynamics.org/conferences/2006/proceed/ papers/ZAGON374.pdf

35. Sterman JD (2000) Business dynamics: systems thinking and modeling for a complex world. Irwin McGraw Hill, Boston

36. WAPP (2012) Business plan - 2012-2015. www.ecowapp.org/?dl_id=384 Accessed 16 Mar 2015

37. Musango JK, Brent AC, Tshangela M (2014) Green economy transitioning of the South African power sector: a System dynamics analysis approach. Dev South Afr 31(5):744-758

38. World Bank (2013) Assessing low-carbon development in Nigeria: an analysis of four sectors. World Bank Publication Edited by Cervigni, R., Rogers, J. A. and Dvorak, I. Retrieved from http://documents.worldbank.org/ curated/en/333931468332952975/pdf/782810REPLACEM00Box377335B00 Public0.pdf. on 15 June 2015

39. Meadows D (1999) Leverage points: places to intervene in a system. Sustainability Institute. Retrieved from http://donellameadows.org/archives/ leverage-points-places-to-intervene-in-a-system/. on March 182015

40. Ventana Systems, Inc (2013) Vensim manual 
41. Hekimoğlu M, Barlas Y (2010) Sensitivity analysis of System dynamics models by behavior pattern measures. Retrieved on March 182015 from www.systemdynamics.org/conferences/2010/proceed

42. Brander M, Sood A, Wylie C, Haughton A., and Lovell J (2011) Technical paper| Electricity-specific emission factors for grid electricity. Ecometrica, Emissionfactors. com.

43. EIA (Energy Information Administration) (2012) Reserve electric generating capacity helps keep the lights on. https://www.eia.gov/todayinenergy/detail. php. Accessed 8 Jun 2015

44. Merriam-Webster, Incorporated (2015) Merriam-Webster dictionary

45. Foster G, Frijters $P$ (2010) The formation of expectations: competing theories and new evidence. Yet to be published work retrieved from https://www.aeaweb.org/conference/2011/retrieve.php?pdfid=267. on 12 October 2015

46. EcoBank (2014) Fully charged: key dynamics in Middle Africa's Power Sector in 2014; executive summary. Middle Africa Insight Series | Power. http:// cdn2.hubspot.net/hub/235203/file-546544071-pdf/Content_reports/Trends_ in_power_2014/ecobank_power_sector_report.pdf. Accessed 13 Oct 2015

47. NERC (2015) Amended Multi Year Tariff Order (MYTO) - 2.1 For the period April 1st, 2015 to December 2018: ORDER No. NERC/REG/3/2015. Retrieved from http://www.nercng.org/index.php/nerc-documents/MYTO-2/. on 13 October 2015

48. Ackermann T (ed) (2005) Wind power in power systems, vol 140. John Wiley, Chichester

49. Al-Naseem OA, Adi AK (2003) Impact of power factor correction on the electrical distribution network of Kuwait-a case study. Online J Power Energy Eng 1:173-176

50. Forrester JW (1961) Industrial dynamics. MIT Press, Cambridge

51. Bergson H (1971) Time and free will

52. KPMG (2014) Sub-Saharan Africa Power Outlook 2014. http://www. subsahara-afrika-ihk.de/wp-content/uploads/2015/01/2014-Sub-SaharanAfrican-Power-Outlook-update.pdf. Accessed 7 Feb 2015

53. Bazilian M, Pielke R (2013) Making energy access meaningful. Issues Sci Technol 29(4):74-78

54. Deloitte \& Touche (2015) Sub-Saharan Africa Power Trends Power disruption in Africa. http://www.sun-connect-news.org/fileadmin/DATEIEN/ Dateien/New/ZA_AfricaPowerTrendsReport_EnergyResources_200515.pdf. Accessed 9 Aug 2016

55. Klaassen E (2011) International comparison of fossil power efficiency and $\mathrm{CO}_{2}$ intensity. ECOFYS, Mitsubishi Research Institute, Japan

56. Wang B, Nistor I, Murty T, Wei YM (2014) Efficiency assessment of hydroelectric power plants in Canada: a multi criteria decision making approach. Energy Econ 46:112-121

57. US Department of the Interior (2005) Reclamation: managing water in the West-hydroelectric power. https://www.usbr.gov/power/ AssessmentReport/USBRHydroAssessmentFinalReportMarch2011.pdf. Accessed 15 Sept 2016

58. EIA (2015) Electric generator capacity factors vary widely across the world. https://www.eia.gov/todayinenergy/detail.php. Accessed 15 Sept 2016

59. Ford A (2001) Waiting for the boom: a simulation study of power plant construction in California. Energy Policy 29(11):847-869

60. Thomas C, Rolls J, and Tennant T (2000) The GHG indicator: UNEP guidelines for calculating greenhouse gas emissions for businesses and non-commercial organisations (p. 61). UNEP

61. Soares C (1998) Gas turbines in simple cycle \& combined cycle applications. In: Dennis R (ed) The Gas Turbine Handbook. NETL, Morgantown

\section{Submit your manuscript to a SpringerOpen ${ }^{\circ}$ journal and benefit from:}

- Convenient online submission

$\checkmark$ Rigorous peer review

- Immediate publication on acceptance

- Open access: articles freely available online

- High visibility within the field

Retaining the copyright to your article 